\title{
Protective Effect of Silymarin against Acrolein-Induced Cardiotoxicity in Mice
}

\author{
Elahe Taghiabadi, ${ }^{1}$ Mohsen Imenshahidi, ${ }^{2}$ Khalil Abnous, ${ }^{3}$ Fatemeh Mosafa, ${ }^{4}$ \\ Mojtaba Sankian, ${ }^{5}$ Bahram Memar, ${ }^{6}$ and Gholamreza Karimi ${ }^{7}$ \\ ${ }^{1}$ Department of Phamacodynamy and Toxicology, School of Pharmacy, Mashhad University of Medical Sciences, \\ Mashhad 9177948564, Iran \\ ${ }^{2}$ Pharmaceutical Research Center, Department of Pharmacodynamy and Toxicology, School of Pharmacy, \\ Mashhad University of Medical Sciences, Mashhad 9177948564, Iran \\ ${ }^{3}$ Department of Pharmaceutical Biotechnology, Mashhad University of Medical Sciences, Mashhad 9177948564, Iran \\ ${ }^{4}$ Biotechnology Research Center and School of Pharmacy, Mashhad University of Medical Sciences, Mashhad 9177948564, Iran \\ ${ }^{5}$ Immunology Research Center, School of Medicine, Mashhad University of Medical Sciences, Mashhad 9177948564, Iran \\ ${ }^{6}$ Department of Pathology, Imam Reza Hospital, Mashhad University of Medical Sciences, Mashhad 9177948564, Iran \\ ${ }^{7}$ Medical Toxicology Research Center and School of Pharmacy, Mashhad University of Medical Sciences, Mashhad 9177948564, Iran
}

Correspondence should be addressed to Gholamreza Karimi, karimig@mums.ac.ir

Received 16 August 2012; Revised 12 November 2012; Accepted 15 November 2012

Academic Editor: Khalid Rahman

Copyright ( $) 2012$ Elahe Taghiabadi et al. This is an open access article distributed under the Creative Commons Attribution License, which permits unrestricted use, distribution, and reproduction in any medium, provided the original work is properly cited.

\begin{abstract}
Reactive $\alpha, \beta$-unsaturated aldehydes such as acrolein (ACR) are major components of environmental pollutants and have been implicated in the neurodegenerative and cardiac diseases. In this study, the protective effect of silymarin (SN) against cardiotoxicity induced by ACR in mice was evaluated. Studies were performed on seven groups of six animals each, including vehicle-control (normal saline $+0.5 \% \mathrm{w} / \mathrm{v}$ methylcellulose), ACR $(7.5 \mathrm{mg} / \mathrm{kg} /$ day, gavage) for 3 weeks, SN (25, 50 and $100 \mathrm{mg} / \mathrm{kg} / \mathrm{day}$, i.p.) plus ACR, vitamin E (Vit E, $100 \mathrm{IU} / \mathrm{kg}$, i.p.) plus ACR, and SN (100 mg/kg, i.p.) groups. Mice received SN 7 days before ACR and daily thereafter throughout the study. Pretreatment with SN attenuated ACR-induced increased levels of malondialdehyde (MDA), serum cardiac troponin I (cTnI), and creatine kinase-MB (CK-MB), as well as histopathological changes in cardiac tissues. Moreover, SN improved glutathione (GSH) content, superoxide dismutase (SOD), and catalase (CAT) activities in heart of ACR-treated mice. Western blot analysis showed that SN pretreatment inhibited apoptosis provoked by ACR through decreasing $\mathrm{Bax} / \mathrm{Bcl}-2$ ratio, cytosolic cytochrome c content, and cleaved caspase-3 level in heart. In conclusion, SN may have protective effects against cardiotoxicity of ACR by reducing lipid peroxidation, renewing the activities of antioxidant enzymes, and preventing apoptosis.
\end{abstract}

\section{Introduction}

Acrolein $\left(\mathrm{ACR}, \mathrm{CH}_{2}=\mathrm{CH}-\mathrm{CHO}\right)$ has been used as an intermediate for production of some organic chemicals and as a biocide in agricultural and industrial water supply systems $[1,2]$.

According to the Environmental Protection Agency classification, ACR is a high-priority air and water toxic agent [3]. ACR, a ubiquitous environmental pollutant, is produced by incomplete burning of plastic, petrol, wood, gasoline and diesel fuel, paraffin wax, tobacco, and frying of foods in oils $[1,2]$. ACR in different levels (10 to $600 \mu \mathrm{g} / \mathrm{kg}$ ) has been found in some foods like cheese, donuts, fish, bread, potatoes, and alcoholic beverages $[4,5]$. Also, ACR is formed endogenously from the polyunsaturated fatty acids oxidation and the metabolism of polyamine and cyclophosphamide $[1,3]$. The sources of ACR that are related to the toxicity and human exposure can be classified into dietary, endogenous, and environmental sources [1]. ACR, a highly reactive $\alpha, \beta$ unsaturated aldehyde, can covalently bind to cell thiols 
and amine groups in sugars, phospholipids, proteins, and DNA bases and induce oxidative stress and proinflammatory effects in various tissues and cells $[6,7]$. ACR provokes its harmful effects through the generation of reactive oxygen species (ROS) and lipid peroxidation in many cell types $[8,9]$. Increased evidence indicates that oxidative stress may possess an important effect in the pathogenesis of cardiovascular disorder including ischemic heart disease, heart failure, and atherosclerosis [10-12].

In addition to oxidative stress, ACR can induce apoptosis in different cells by activation of the mitochondrial pathway or death receptor signaling $[13,14]$. Some experimental studies indicate that ACR can exert detrimental effects in adult mice cardiomyocytes and heart tissues through apoptotic cell death $[6,9]$. Apoptosis has been involved in the toxicity of many chemicals and environmental pollutants [15]. Apoptosis is a physiological cell death that plays a significant role in development and the maintenance of cell homeostasis. An imbalance between apoptotic cell death and cell proliferation damages the normal state and leads to neurodegeneration disorders and heart diseases [14, $16]$.

Silymarin (SN), a polyphenolic flavonoid, is a standardized extract obtained from the seeds and fruits of milk thistle. It is a mixture of some isomeric flavonolignans including silybin, isosilybin, silydianin, and silychristin [17]. SN indicates effective antioxidant properties [18] in addition to anti-inflammatory [19] and anticarcinogenic actions [20] in animal and human studies. SN has been used clinically to improve chronic inflammatory liver diseases and hepatic cirrhosis. Hepatoprotection can be associated with its antioxidant effects through scavenging free radicals and increasing endogenous antioxidant defenses such as intracellular glutathione (GSH) [21]. It has been demonstrated that $\mathrm{SN}$ and milk thistle methanolic extract protect against renal toxicity induced by cisplatin due to the decrease in blood urea nitrogen (BUN), serum creatinine, and tubular damage in rats [22]. It is reported that $\mathrm{SN}$ can improve cisplatininduced increase in serum alanine aminotransferase (ALT) and aspartate aminotransferase (AST), malondialdehyde (MDA), and nitric oxide (NO), as well as the decrease in GSH and the activities of antioxidant enzymes like superoxide dismutase (SOD) and glutathione peroxidase (GSHPx) in liver of rats [23]. SN also attenuates cardiotoxicity and nephrotoxicity induced by adriamycin in rats through the inhibition of lipid peroxidation and GSH depletion in these tissues [24]. Further study indicates that SN can eliminate or significantly decrease the elevation of cytochrome P450 isoform CYP1A1, inducible nitric oxide synthase (iNOS), and metallothionein I-II (MT) expressions in liver, kidney, and heart of the pyridine-treated Syrian hamsters [25]. It has been indicated that pretreatment of male ICR mice with $\mathrm{SN}$ protects against doxorubicin-induced oxidative stress and cell death occurring by apoptosis or necrosis in the liver [26]. In addition, SN can considerably ameliorate cisplatin cardiotoxicity by the decrease in serum biochemical marker and MDA level and the increase in GSH content, SOD activity, and the content of total protein [27]. Therefore, we designed the present experiments to evaluate the protective effect of SN against cardiotoxicity induced by ACR subacute exposure in mice.

\section{Materials and Methods}

2.1. Chemicals. ACR, SN, phenylmethanesulfonyl fluoride (PMSF), complete protease inhibitor cocktail, and reduced GSH were obtained from Sigma-Aldrich Chemical Company. Vitamin E (Vit E, DL- $\alpha$-Tocopherol acetate) was provided from OSVE Pharmaceutical Co. (Tehran, Iran). Sodium dodecyl sulphate (SDS), MDA, thiobarbituric acid (TBA), $\mathrm{N}, \mathrm{N}, \mathrm{N}^{\prime}, \mathrm{N}^{\prime}$-Tetramethylethylenediamine (TEMED), and $\beta$-Mercaptoethanol $(\beta$-ME) were provided from Merck. Rabbit monoclonal caspase-3 antibody, rabbit monoclonal caspase-8 antibody, rabbit polyclonal Hsp27 antibodies, rabbit polyclonal Hsp70 antibody, rabbit polyclonal Hsp90 antibody, rabbit monoclonal Bcl-2 antibody, rabbit polyclonal Bax antibody, rabbit polyclonal cytochrome c antibody, antirabbit IgG, horseradish peroxidase-conjugated antibody, mouse monoclonal $\beta$-actin antibody, and anti-mouse IgG, horseradish peroxidase-conjugated antibody were purchased from Cell Signaling. Polyvinylidene fluoride (PVDF) membrane and Bradford protein assay kit were obtained from BioRad. Assay kits for antioxidant enzymes including superoxide dismutase (SOD) and catalase (CAT) were purchased from Biovision (CA, USA), and assay kit for cardiac troponin I (cTnI) was provided from Life Diagnostics, Inc. Assay kit for creatine kinase-MB (CK-MB) was supplied from Pars Azmun (Tehran, Iran). BCA protein assay kit, mitochondria isolation kit for tissue and western blotting detecting reagents (ECL), was supplied from Pierce. All other chemicals were of the highest grade commercially available.

2.2. Animal Treatment. Male albino Razi mice (weighing approximately $25-35 \mathrm{~g}$ ) were obtained from the animal house of the Pharmaceutical Sciences Research Center of Mashhad University of Medical Sciences. Animals were housed in a ventilated room under a $12 / 12 \mathrm{~h}$ light/dark cycle at $21 \pm 2{ }^{\circ} \mathrm{C}$ and had free access to water and food throughout the experimental period. All animal experiments were carried out in accordance with Mashhad University of Medical Sciences, Ethical Committee Acts.

The mice were divided into seven groups of six animals each. The chemicals were administrated in the morning (between 9:00 and 11:00 AM) [28].

Group 1 (Vehicle-Control Group). The vehicle-control group received normal saline $+0.5 \% \mathrm{w} / \mathrm{v}$ methylcellulose as a vehicle, orally by gavage once a day, for 3 weeks.

Group 2 (ACR-Treated Group (ACR Group)). In this group, animals were treated with ACR $7.5 \mathrm{mg} / \mathrm{kg}$ per day in normal saline $+0.5 \% \mathrm{w} / \mathrm{v}$ methylcellulose, orally by gavage once a day, for 3 weeks.

Groups 3, 4, and 5 (SN + ACR-Treated Groups (ACR + $S N$ Group)). SN was dispersed in normal saline $+0.5 \%$ $\mathrm{w} / \mathrm{v}$ methylcellulose and was injected at doses 25,50 , and $100 \mathrm{mg} / \mathrm{kg}$ per day intraperitoneally to mice, 7 days before 
ACR $(7.5 \mathrm{mg} / \mathrm{kg}$ per day, once a day, orally) and daily thereafter throughout the study (3 weeks) [22].

Group 6 (Vit E + ACR-Treated Group (ACR + Vit E Group)). Vit E $(100 \mathrm{IU} / \mathrm{Kg})$ was dispersed in normal saline $+0.5 \%$ w/v methylcellulose and, intraperitoneally, was injected three times per week for 3 weeks, and ACR was administrated orally by gavage $(7.5 \mathrm{mg} / \mathrm{kg}$ per day, once a day) for 3 weeks. Vit E has been considered as a positive control [28].

Group 7 (SN-Treated Group (SN Group)). In this group, mice received SN (100 mg/kg per day, intraperitoneally) for 4 weeks.

At the end of the experiment time, after overnightfasted state, the animals from each group were sacrificed by decapitation. Trunk blood samples were immediately collected in dry tubes and allowed to clot then centrifuged at $2000 \times \mathrm{g}$ for $15 \mathrm{~min}$ to separate the sera that were kept at $-70^{\circ} \mathrm{C}$ for biochemical analysis of $\mathrm{CK}-\mathrm{MB}$ and $\mathrm{cTnI}$ levels. Abdomen of each mouse was opened and hearts were carefully removed, washed in ice-cold isotonic saline, immediately immersed in liquid nitrogen, and stored at $-80^{\circ} \mathrm{C}$ for various analyses.

\subsection{Cardiac Oxidative Stress Assessment}

2.3.1. Cardiac Lipid Peroxidation and Reduced GSH Content. For measurement of MDA (as a marker of lipid peroxidation), the heart was homogenized in ice-cold solution of $1.15 \% \mathrm{KCl}$ to produce $10 \%$ homogenate $(\mathrm{w} / \mathrm{v})$. The homogenate was centrifuged at $3000 \times \mathrm{g}$ for $10 \mathrm{~min}$, and the obtained supernatant was used as total heart homogenized sample. The levels of protein and MDA were measured in the supernatants.

The protein content was evaluated using Bradford Protein Assay kit (Bio-Rad Laboratories) and Bovine serum albumin (BSA) as standard. According to the instruction of manufacture, $10 \mu \mathrm{L}$ of sample supernatants or BSA standards were pipetted into separated microtiter plate wells, and then $200 \mu \mathrm{L}$ diluted dye reagent (containing 1 part Dye Reagent Concentrate with 4 parts distilled, deionized water) was added to each well and thoroughly mixed on a plate shaker. After 5 minutes incubation at room temperature, the absorbance of reactions was measured at $595 \mathrm{~nm}$. The protein concentration was calculated by the simultaneously prepared calibration curves using BSA standards.

Lipid peroxidation products were assessed by measuring MDA level according to the method of Niehaus and Samuelsson [29]. The level of MDA in the supernatant was determined spectrophotometrically by measuring thiobarbituric acid-reactive substances with a maximum absorbance at $532 \mathrm{~nm}$. Briefly, $0.5 \mathrm{~mL}$ of the sample was mixed with $3 \mathrm{~mL}$ of $1 \%$ phosphoric acid and $1 \mathrm{~mL}$ of $0.6 \%$ TBA solution. The mixture was heated in a boiling water bath for $45 \mathrm{~min}$ and cooled to the room temperature. Then, $4 \mathrm{~mL}$ of n-butanol was added, and mixture was vortexed and centrifuged at $3000 \times \mathrm{g}$ for $10 \mathrm{~min}$. The absorbance of butanol phase (supernatant) was measured at $532 \mathrm{~nm}$. Tissue MDA content was expressed as nmol/mg protein.
Cardiac GSH content was determined according to the method of Moron et al. [30]. The heart was homogenized in ice cold phosphate buffered saline (PBS), $\mathrm{pH} 7.4$, to obtain $10 \%$ homogenate $(\mathrm{w} / \mathrm{v})$. The homogenate was centrifuged at $3000 \times \mathrm{g}$ for $10 \mathrm{~min}$, and the collected supernatant was considered as total heart homogenized sample. The contents of protein and GSH were assessed in the supernatants. The protein content was determined using Bradford Protein Assay kit (Bio-Rad Laboratories) and BSA as standard. Reduced GSH content was measured using 5,5' -dithiobis(2nitrobenzoic acid) (DTNB) which generated a yellowcolored 5-thio-2-nitrobenzoic acid (TNB). In short, equal volumes of sample and $20 \%$ trichloroacetic acid (TCA) were mixed and centrifuged at $3000 \times \mathrm{g}$ for $5 \mathrm{~min}$. $0.5 \mathrm{~mL}$ of supernatant was added to $2 \mathrm{~mL}$ PBS (0.1 M, pH 8.0) and $0.5 \mathrm{~mL}$ of $0.04 \%$ DTNB reagent. Then, yellow color developed was measured spectrophotometrically at $412 \mathrm{~nm}$. Tissue GSH content was expressed as $\mu \mathrm{g} / \mathrm{mg}$ protein.

2.3.2. Cardiac Antioxidant Enzymes. The activity of SOD in heart tissue was determined by available kit provided from Biovision. The heart was homogenized in ice-cold $0.1 \mathrm{M}$ Tris/HCl, pH 7.4 containing $0.5 \%$ Triton $\mathrm{X}-100,5 \mathrm{mM} \beta$-ME, $0.1 \mathrm{mg} / \mathrm{mL}$ PMSF and centrifuged at $14,000 \times \mathrm{g}$ for 5 minutes at $4^{\circ} \mathrm{C}$ to obtain supernatant. The contents of protein and SOD activity were assessed in the supernatants. The protein content of obtained supernatants was determined using BCA Protein Assay kit (Pierce) and BSA as standard. According to the instruction of manufacture, $10 \mu \mathrm{L}$ of sample supernatants or BSA standards was pipetted into separated microtiter plate wells, and then $200 \mu \mathrm{L}$ BCA Working Reagent (a mixture containing 50 part BCA Reagent A and 1 part BCA Reagent B) was added to each well and carefully mixed on a plate shaker for 30 seconds. After $30 \mathrm{~min}$ incubation at $37^{\circ} \mathrm{C}$, the absorbance of reactions was measured at $562 \mathrm{~nm}$. The protein concentration was determined by the simultaneously prepared calibration curves using BSA standards.

In this assay, xanthine and xanthine oxidase generate superoxide anion that reacts with tetrazolium chloride to produce a yellow color formazan dye. SOD activity was measured at $450 \mathrm{~nm}$. The activity of SOD in heart tissue was expressed as (inhibition rate\%)/mg protein.

The activity of CAT was determined using commercially kit obtained from Biovision. To evaluate CAT activity, the heart was homogenized in cold assay buffer and centrifuged at $10,000 \times \mathrm{g}$ for $15 \mathrm{~min}$ at $4^{\circ} \mathrm{C}$ to obtain supernatant. The protein content and CAT activity were measured in the supernatants. The protein content of supernatants was determined using BCA Protein Assay kit (Pierce) and BSA as standard. One unit of CAT was defined as the amount of enzyme needed to decompose $1 \mu \mathrm{M}$ of $\mathrm{H}_{2} \mathrm{O}_{2}$ in $1 \mathrm{~min}$. The rate of decomposition of $\mathrm{H}_{2} \mathrm{O}_{2}$ was measured spectrophotometrically at $570 \mathrm{~nm}$. The activity of CAT in cardiac tissue was expressed as $\mathrm{mU} / \mathrm{mg}$ protein.

2.4. Serum Biomarkers of Cardiotoxicity. Serum cTnI was determined using a mice-specific ELISA kit from Life Diagnostics (West Chester, PA), and serum CK-MB was 


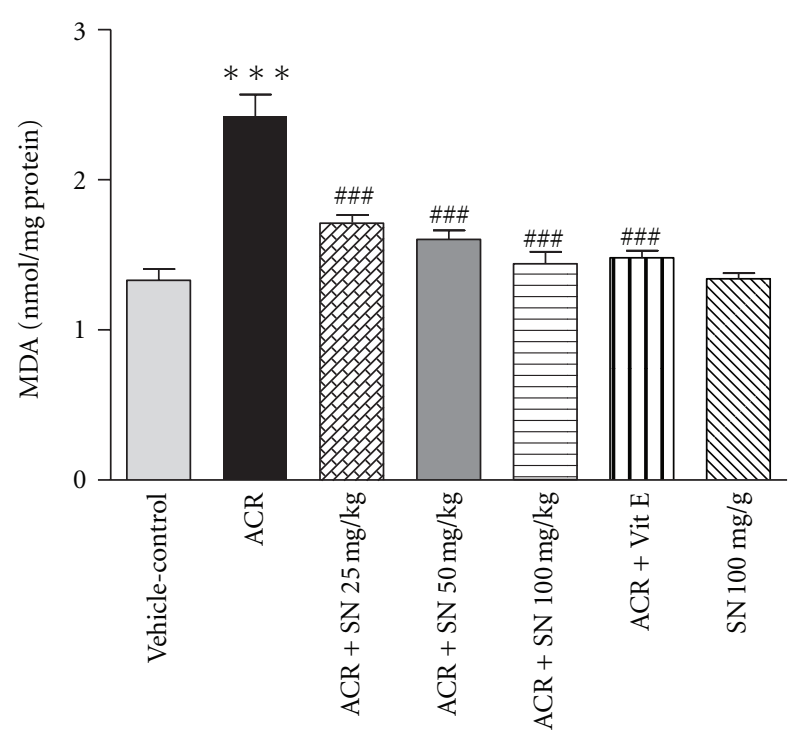

FIGURE 1: The effect of ACR and SN pretreatment on MDA level in heart of mice. Vehicle-control group received normal saline $+0.5 \%$ w/v methylcellulose, orally for 3 weeks. ACR was given $(7.5 \mathrm{mg} / \mathrm{kg}$, orally) for 3 weeks. SN was injected 7 days before ACR and daily thereafter throughout the study (3 weeks). Vit E (100 IU/Kg, three times per week) plus ACR were administrated for 3 weeks. SN alone at dose $(100 \mathrm{mg} / \mathrm{kg}$, intraperitoneally) was treated for 4 weeks. Data are expressed as mean \pm SEM. ${ }^{* * *} P<0.001$ versus vehicle-control group, ${ }^{\# \#} P<0.001$ versus ACR group, Tukey-Kramer test, $n=6$.

measured using a commercial colorimetric kit from Pars Azmun (Tehran, Iran) according to the instructions of manufacturer.

2.5. Histopathological Study. The hearts were fixed in $10 \%$ buffered formalin for at least $24 \mathrm{~h}$ and then were processed for microscopical assay by a standard protocol. The paraffin sections about $5 \mu \mathrm{m}$ were stained with hematoxylin and eosin to evaluate under light microscope. Histopathological criteria such as inflammation and edema were determined semiquantitatively from mild $(+)$ to moderate $(++)$, sever $(+++)$, and very sever $(++++)$.

2.6. Western Blot Analysis. The heart was homogenized in lysis buffer containing $50 \mathrm{mM}$ Tris- $\mathrm{HCl}, \mathrm{pH} 7.4,2 \mathrm{mM}$ ethylenediaminetetraacetic acid (EDTA), $2 \mathrm{mM}$ ethylene glycol-bis(2-aminoethylether)- $\mathrm{N}, \mathrm{N}, \mathrm{N}^{\prime}, \mathrm{N}^{\prime}$-tetraacet acid (EGTA), $10 \mathrm{mM}$ sodium fluoride, $1 \mathrm{mM}$ sodium orthovanadate, $10 \mathrm{mM} \beta$-glycerophosphate, $0.2 \%$ sodium deoxycholate, $1 \mathrm{mM}$ PMSF, and complete protease inhibitor cocktail. After centrifugation at $10,000 \times \mathrm{g}$ for $10 \mathrm{~min}$, the protein concentration of supernatant was measured using Bradford Protein Assay kit (Bio-Rad Laboratories) and BSA as standard. The supernatant was stored at $-80^{\circ} \mathrm{C}$. The total of $50 \mu \mathrm{g}$ of whole protein was used for evaluation of the content of Bax, Bcl-2, caspase-3, caspase-8, Hsp27, Hsp70, and Hsp90.

To assess the level of cytochrome $\mathrm{c}$ in cytosolic fraction, the mitochondria isolation kit for tissue (Pierce Biotechnology, Rockford, IL, USA) was used to isolate the cytosolic fraction based on the instruction of manufacturer. Briefly, fresh heart tissues were washed with PBS and were cut to small pieces. Then, BSA/reagent was added, and tissues were homogenized on ice using 40 strokes with dounce tissue grinder. After adding reagent $\mathrm{C}$, homogenate was centrifuged at $700 \times \mathrm{g}$ for $10 \mathrm{~min}$ at $4^{\circ} \mathrm{C}$. Obtained supernatant was centrifuged at $3000 \times \mathrm{g}$ for $15 \mathrm{~min}$ at $4^{\circ} \mathrm{C}$, removed from the pellet, and considered as cytosolic fraction. Then, the concentration of protein in cytosolic fraction was determined. The total of $50 \mu \mathrm{g}$ of the cytosolic fraction protein was used for evaluation of cytochrome c content.

Western blotting was carried out to assess the levels of Bax, Bcl-2, cytochrome c, caspase-3, caspase-8, Hsp27, Hsp70, and Hsp90 by appropriate antibodies, followed by a horseradish peroxidase-conjugated secondary antibody. Proteins $(50 \mu \mathrm{g})$ were solubilised in Laemmli sample buffer. Then, the samples were boiled for $5 \mathrm{~min}$ at $95^{\circ} \mathrm{C}$, and the denatured samples were separated by $12 \%$ SDSpolyacrylamide gel electrophoresis and transferred to PVDF membrane. Following the transfer, the membranes were blocked by overnight incubation at $4{ }^{\circ} \mathrm{C}$ in a $5 \%$ skim milk. After blocking, blots were incubated with antibodies: Bax (Cell Signaling no. 2772), Bcl-2 (Cell Signaling no. 2870), cytochrome c (Cell Signaling no. 4272), caspase-3 (Cell Signaling no. 9665), caspase-8 (Cell Signaling no. 4790), Hsp27 (Cell Signaling no. 2442), Hsp70 (Cell Signaling no. 4872), and Hsp90 (Cell Signaling no. 4874) at 1000-fold dilutions for $2 \mathrm{~h}$ at room temperature. Mouse monoclonal $\beta$-actin antibody (Cell Signaling no. 3700S) was used to confirm equal loading conditions. The blots were washed three times with TBST (TBS with $0.1 \%$ Tween 20) and then incubated with horseradish peroxidase-conjugated antirabbit antibody (no. 7074 Cell Signaling) or horseradish peroxidase-conjugated anti-mouse antibody (no. 7076S Cell Signaling) at 1:3000 dilution for $1 \mathrm{~h}$ at room temperature, again followed by three washes with TBST. Finally, protein bands were detected using enhanced chemiluminescnce (ECL) reagent (Pierce ECL western blotting substrate) and Alliance 4.7 Geldoc (UK). Protein bands were analyzed using UVtec software (UK). The protein levels were normalized against $\beta$-actin intensity.

2.7. Statistical Analysis. The mean \pm SEM was determined for each study group and tested with analysis of variance followed by the multiple comparison test of Tukey-Kramer. Discrepancies with $P<0.05$ were considered significant.

\section{Results}

3.1. Effect of SN on Lipid Peroxidation and GSH Content. Oxidative stress can be evaluated by assessment of the end products of oxidative damage such as MDA that indicated the lipid peroxidation of cell membrane and the content of GSH, which scavenges free radicals and detoxifies different xenobiotics [31]. The level of MDA in the cardiac tissue was shown in Figure 1. Cardiac level of MDA was significantly increased in ACR-treated mice compared to vehicle-control $(P<0.001)$. Pretreatment with SN in ACR + SN groups 


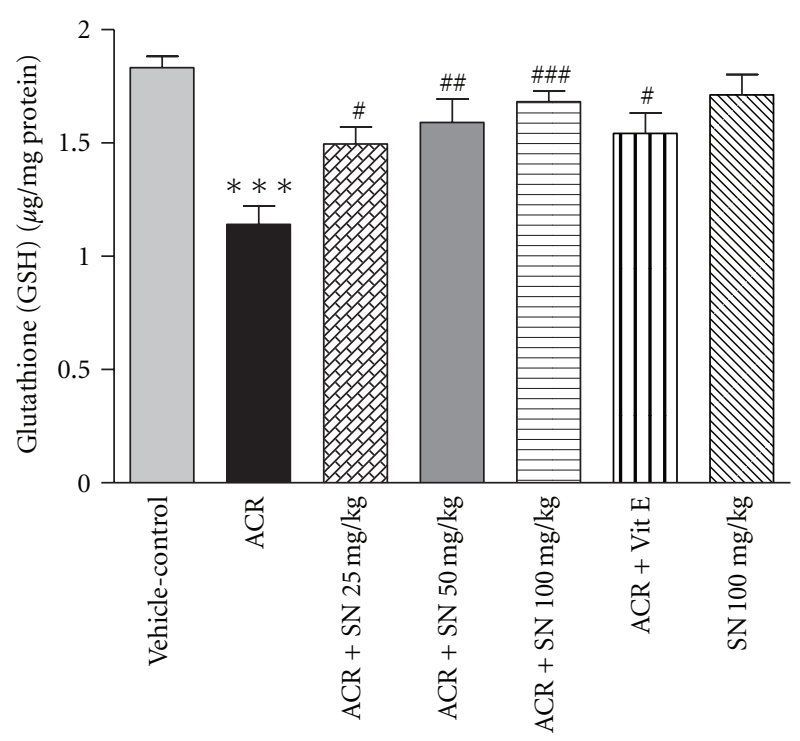

FIGURE 2: The effect of ACR and SN pretreatment on GSH content in heart of mice. Vehicle-control group received normal saline $+0.5 \% \mathrm{w} / \mathrm{v}$ methylcellulose, orally for 3 weeks. ACR was given $(7.5 \mathrm{mg} / \mathrm{kg}$, orally) for 3 weeks. SN was injected 7 days before ACR and daily thereafter throughout the study (3 weeks). Vit E (100 IU/Kg, three times per week) plus ACR were administrated for 3 weeks. SN alone at dose $(100 \mathrm{mg} / \mathrm{kg}$, intraperitoneally) was treated for 4 weeks. Data are expressed as mean \pm SEM. ${ }^{* * *} P<$ 0.001 versus vehicle-control group, ${ }^{\# \#} P<0.001,{ }^{\# \#} P<0.01$, and ${ }^{\#} P<0.05$ versus ACR group, Tukey-Kramer test, $n=6$.

resulted in a significant decrease in MDA value compared to ACR-treated group $(P<0.001)$. SN alone at dose $100 \mathrm{mg} / \mathrm{Kg}$ did not increase MDA level compared to vehicle-control group. The content of GSH in heart was shown in Figure 2. In ACR-treated mice, cardiac content of GSH was significantly reduced compared to vehicle-control $(P<0.001)$. However, pretreatment with $\mathrm{SN}$ in ACR + SN groups significantly increased the content of GSH compared to ACR-treated mice $(P<0.05)$. The result of this study indicated that treatment of mice with SN alone at dose $100 \mathrm{mg} / \mathrm{Kg}$ did not change the content of GSH compared to vehicle-control group.

3.2. Effect of SN on Cardiac Antioxidant Enzymes. The antioxidant enzymes SOD and CAT are members of endogenous antioxidants that play an important role in protection of the biological systems against oxidative damages [31]. The activities of SOD and CAT in cardiac tissue were demonstrated in Figures 3 and 4, respectively. Administration of ACR to mice significantly reduced the cardiac activities of SOD and CAT as compared to the vehicle-control $(P<0.001)$. However, a significant increase in the activities of SOD and CAT was observed upon pretreatment with $\mathrm{SN}$ in ACR + SN groups compared to ACR-treated group $(P<0.05$ and $P<0.001$, resp.). Data showed that treatment with $\mathrm{SN}$ alone did not decrease the cardiac activities of SOD and CAT compared to the vehicle-control.

3.3. Effect of SN on Serum Biomarkers and Histopathological Study. cTnI and CK-MB are released from damaged

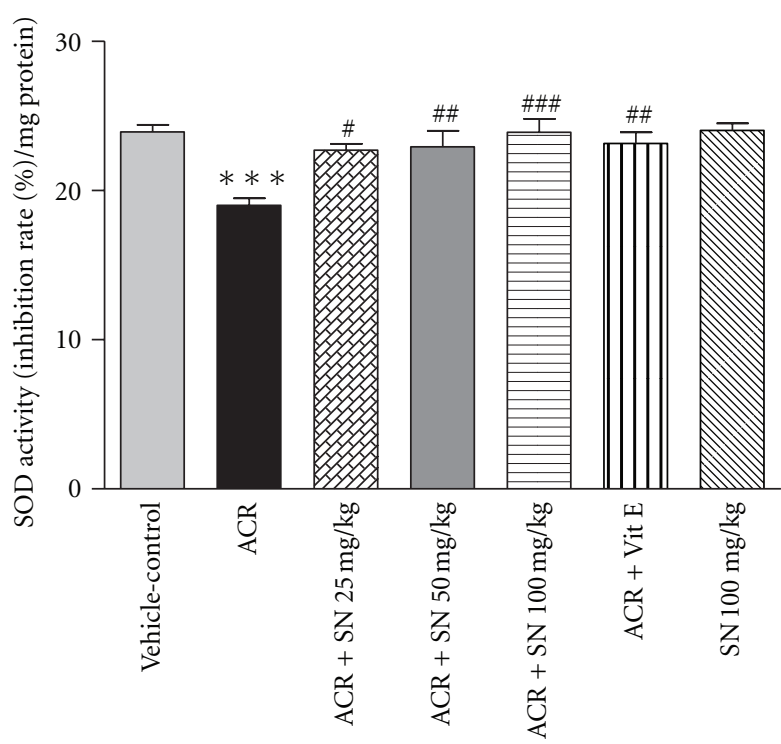

FIGURE 3: The effect of ACR and SN pretreatment on SOD activity in heart of mice. Vehicle-control group received normal saline $+0.5 \% \mathrm{w} / \mathrm{v}$ methylcellulose, orally for 3 weeks. ACR was given $(7.5 \mathrm{mg} / \mathrm{kg}$, orally) for 3 weeks. SN was injected 7 days before ACR and daily thereafter throughout the study (3 weeks). Vit E (100 IU/Kg, three times per week) plus ACR were administrated for 3 weeks. SN alone at dose $(100 \mathrm{mg} / \mathrm{kg}$, intraperitoneally) was treated for 4 weeks. Data are expressed as mean \pm SEM. ${ }^{* * *} P<$ 0.001 versus vehicle-control group, ${ }^{\# \#} P<0.001$, ${ }^{\# \#} P<0.01$, and ${ }^{\#} P<0.05$ versus ACR group, Tukey-Kramer test, $n=6$.

myocytes, and these are sensitive factors of myocardial damages [32]. Assessment of cTnI and CK-MB levels in serum was shown in Figures 5 and 6, respectively. The present data revealed that the levels of $\mathrm{cTnI}$ and CK-MB in serum were significantly increased in ACR-treated mice as compared to vehicle-control $(P<0.001)$. Pretreatment with $\mathrm{SN}$ in ACR $+\mathrm{SN}$ groups significantly decreased these biomarkers compared to ACR-treated group $(P<0.01$ and $P<0.001$, resp.). The levels of cTnI and CK-MB in serum showed no significant changes in mice treated with $\mathrm{SN}$ alone compared to the vehicle-control.

Cardiotoxicity induced by ACR was further evaluated by hematoxylin and eosin stained sections. Hearts from vehiclecontrol group and $\mathrm{SN}$ alone at dose $(100 \mathrm{mg} / \mathrm{Kg})$ indicated normal myocardium architecture (Figures $7(\mathrm{a})$ and $7(\mathrm{~g})$ ). As shown in Figure 7(b), histological findings indicated abnormalities and toxic effects in cardiac tissues of mice exposed to ACR. Prominent interstitial edema $(+++)$ and focal moderate interstitial inflammation $(++)$ were observed in heart of ACR-treated mice. Pretreatment with SN in ACR $+\mathrm{SN}$ groups reduced myocardial damages (Figures $7(\mathrm{c}$ ), 7(d), 7(e), and 7(f), resp.).

\subsection{Effect of SN on Cardiac Apoptosis by Western Blot Analysis.} The cardiac level of proteins involved in apoptosis pathway was shown in Figures 8-14.

The Bcl-2 family of proteins is considered to reside in the mitochondrial outer membrane and is involved in apoptosis pathway by modulating the membrane permeability. Bax and 


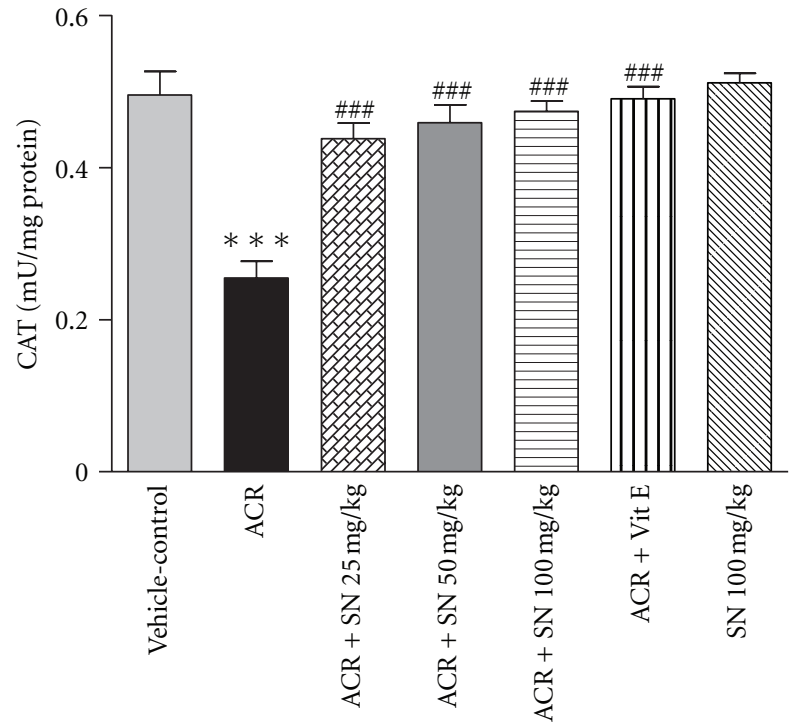

FIGURE 4: The effect of ACR and SN pretreatment on CAT activity in heart of mice. Vehicle-control group received normal saline $+0.5 \%$ $\mathrm{w} / \mathrm{v}$ methylcellulose, orally for 3 weeks. ACR was given $(7.5 \mathrm{mg} / \mathrm{kg}$, orally) for 3 weeks. SN was injected 7 days before ACR and daily thereafter throughout the study (3 weeks). Vit E (100 IU/Kg, three times per week) plus ACR were administrated for 3 weeks. SN alone at dose $(100 \mathrm{mg} / \mathrm{kg}$, intraperitoneally) was treated for 4 weeks. Data are expressed as mean \pm SEM. ${ }^{* * *} P<0.001$ versus vehicle-control group, ${ }^{\# \#} P<0.001$ versus ACR group, Tukey-Kramer test, $n=6$.

BcL-2 are two members of the Bcl-2 family that possess an important effect in the regulation of apoptosis. To assess the protective effect of $\mathrm{SN}$ on ACR-induced apoptosis in heart of mice, the Bax/Bcl-2 ratio was evaluated $[16,33]$. As shown in Figures $8(\mathrm{a})$ and $8(\mathrm{~b})$, administration of ACR to mice significantly upregulated the $\mathrm{Bax} / \mathrm{Bcl}-2$ ratio compared to vehicle-control $(P<0.001)$, and pretreatment with $\mathrm{SN}$ in $\mathrm{ACR}+\mathrm{SN}$ groups significantly attenuated the $\mathrm{Bax} / \mathrm{Bcl}-2$ ratio compared to ACR-treated mice $(P<0.001)$. The current data showed that treatment of mice with SN alone did not upregulate the $\mathrm{Bax} / \mathrm{Bcl}-2$ ratio in heart tissues compared to the vehicle-control.

The libration of cytochrome $\mathrm{c}$ from the mitochondria to the cytoplasm leads to activation of the caspases involved in intrinsic apoptotic pathway, and also cytochrome $\mathrm{c}$ is considered one of the upstream signals for induction of caspase-3 $[16,34]$. The western blot analysis was conducted to evaluate the effects of ACR and SN on the cardiac level of cytochrome $\mathrm{c}$ in cytosolic fraction. As shown in Figures 9(a) and 9(b), the content of cytochrome $\mathrm{c}$ in cytosolic fraction was significantly increased in ACR-treated animals as compared to vehicle-control group $(P<0.001)$. However, pretreatment with $\mathrm{SN}$ in $\mathrm{ACR}+\mathrm{SN}$ groups exerted a significant decrease in the content of cytosolic cytochrome $\mathrm{c}$ as compared to ACR-treated mice $(P<0.001)$. SN alone did not change the content of cytochrome $\mathrm{c}$ in the cytosolic fraction compared to vehicle-control.

Caspase-3 is an important effector caspase (the executioner caspase) which can be activated during the apoptotic pathway [35]. To assess the effects of ACR and SN on the

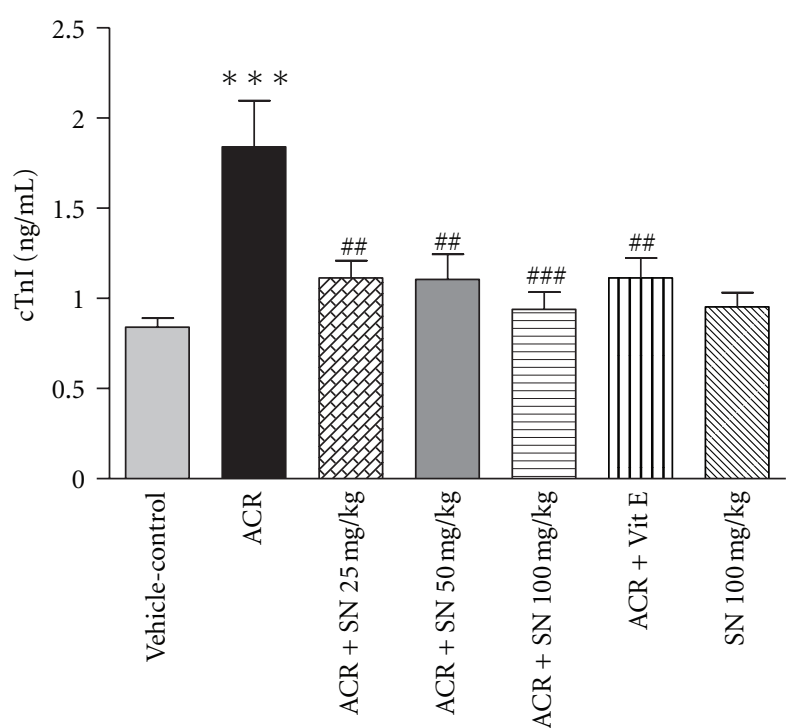

FIGURE 5: The effect of ACR and SN pretreatment on serum cTnI level. Vehicle-control group received normal saline $+0.5 \%$ w/v methylcellulose, orally for 3 weeks. ACR was given $(7.5 \mathrm{mg} / \mathrm{kg}$, orally) for 3 weeks. SN was injected 7 days before ACR and daily thereafter throughout the study (3 weeks). Vit E (100 IU/Kg, three times per week) plus ACR were administrated for 3 weeks. SN alone at dose $(100 \mathrm{mg} / \mathrm{kg}$, intraperitoneally) was treated for 4 weeks. Data are expressed as mean \pm SEM. ${ }^{* * *} P<0.001$ versus vehicle-control group, ${ }^{\# \#} P<0.001$ and ${ }^{\# \#} P<0.01$ versus ACR group, TukeyKramer test, $n=6$.

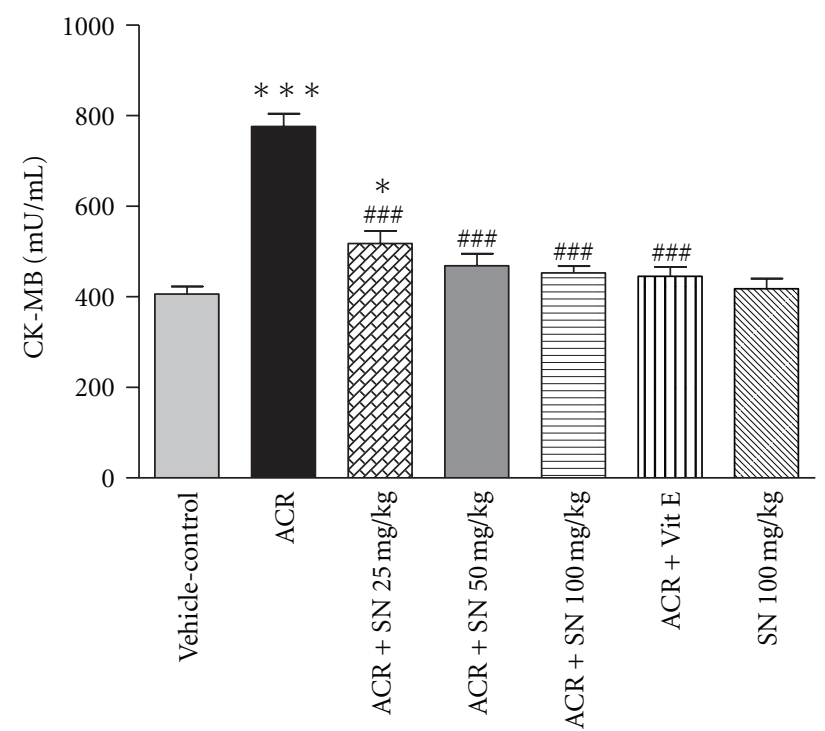

FIGURE 6: The effect of ACR and SN pretreatment on serum CK$\mathrm{MB}$ level. Vehicle-control group received normal saline $+0.5 \% \mathrm{w} / \mathrm{v}$ methylcellulose, orally for 3 weeks. ACR was given $(7.5 \mathrm{mg} / \mathrm{kg}$, orally) for 3 weeks. SN was injected 7 days before ACR and daily thereafter throughout the study (3 weeks). Vit E (100 IU/Kg, three times per week) plus ACR were administrated for 3 weeks. SN alone at dose $(100 \mathrm{mg} / \mathrm{kg}$, intraperitoneally) was treated for 4 weeks. Data are expressed as mean \pm SEM. ${ }^{* * *} P<0.001$ and $* P<0.05$ versus vehicle-control group, ${ }^{\# \#} P<0.001$ versus ACR group, TukeyKramer test, $n=6$. 


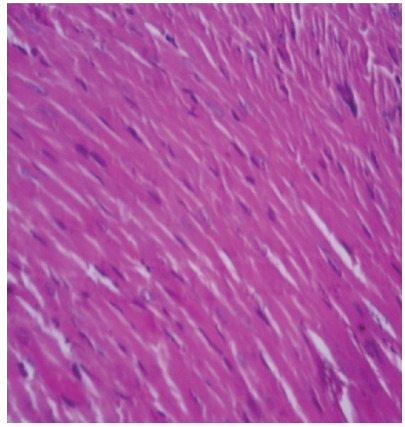

(a)

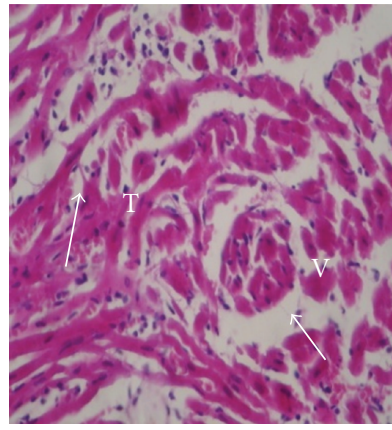

(b)

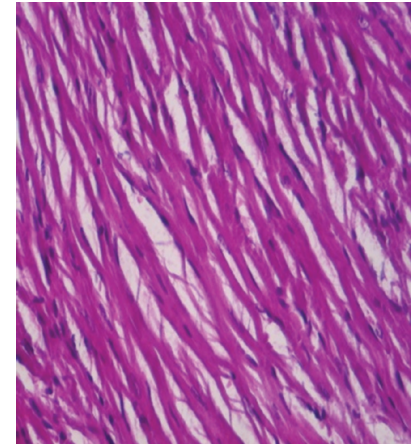

(c)

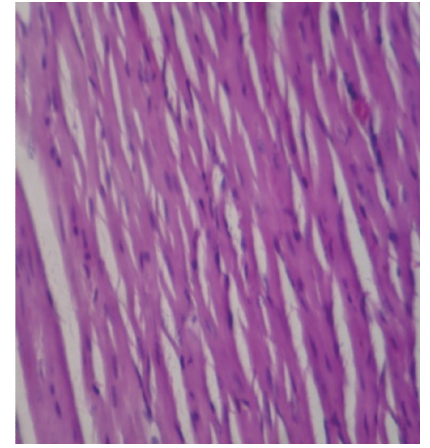

(d)

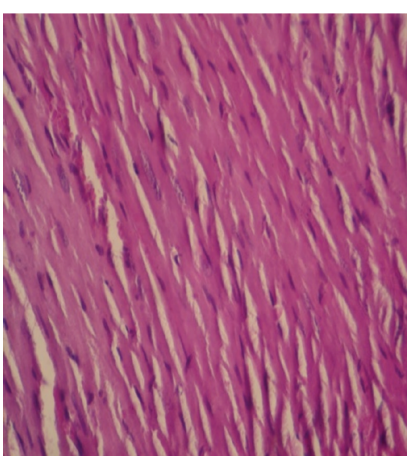

(e)

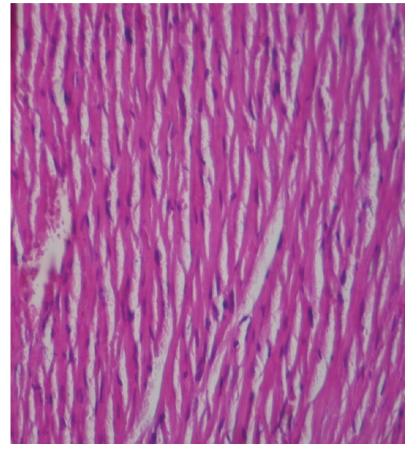

(f)

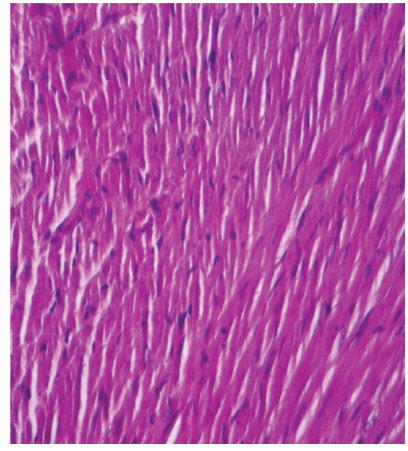

(g)

Figure 7: Cardiac tissues of vehicle-control mice show normal histological pattern. Hematoxylin and eosin $\times 400$. (a) ACR-treated mice indicate prominent interstitial edema $(\mathrm{V})$ and focal moderate interstitial inflammation $(\mathrm{T})$ in heart tissues. Hematoxylin and eosin $\times 400$. (b) Cardiac sections of mice treated with SN (25, 50, and $100 \mathrm{mg} / \mathrm{Kg}$, i.p.) plus ACR and Vit E plus ACR demonstrate the decrease in damages. Hematoxylin and eosin $\times 400$. ((c), (d), (e), and (f), resp.) Cardiac tissues of animals which were injected with SN (100 mg/Kg) show normal myocardium architecture. Hematoxylin and eosin $\times 400$. (g) Vehicle-control group received normal saline $+0.5 \%$ w/v methylcellulose, orally for 3 weeks. ACR was given $(7.5 \mathrm{mg} / \mathrm{kg}$, orally) for 3 weeks. SN was injected 7 days before ACR and daily thereafter throughout the study ( 3 weeks). Vit E (100 IU/Kg, three times per week) plus ACR were administrated for 3 weeks. SN alone at dose (100 mg/kg, intraperitoneally) was treated for 4 weeks.

activation of caspase-3, western blot analysis was conducted to determine the level of cleaved caspase- 3 and procaspase3 in heart tissues. Figures $10(\mathrm{a})$ and 10 (b) indicated that administration of ACR to mice significantly increased the level of cleaved caspase-3 as compared to vehicle-control $(P<0.001)$, and pretreatment with $\mathrm{SN}$ in $\mathrm{ACR}+\mathrm{SN}$ groups significantly decreased the level of cleaved caspase3 compared to ACR-treated animals $(P<0.001)$. Also, data showed that the level of cleaved caspase- 3 was alleviated in ACR + Vit E group. SN treatment alone at dose $100 \mathrm{mg} / \mathrm{Kg}$ did not increase the level of cleaved caspase-3 compared to vehicle-control in heart tissue.

The extrinsic pathway of apoptosis is mediated by death receptors that lead to activation of the initiator caspase8 [36]. To examine the effects of ACR and SN on the activation of caspase-8, western blot analysis was performed to determine the expression of procaspase- 8 and cleaved caspase- 8 in cardiac tissues. As shown in Figures 11(a) and 11(b), administration of ACR to animals indicated no significant change in the level of cleaved caspase- 8 compared to the vehicle-control $(P>0.05)$, and the levels of cleaved caspase- 8 were not different significantly in all groups $(P>$ $0.05)$.
Heat shock proteins (Hsps) are considered to have the beneficial effects in the biological systems. In response to several stimuli like oxidative stress, the expression of Hsps is increased, and some of them such as Hsp27, Hsp70, and Hsp90 can protect cells against oxidative damages and apoptosis [37]. To investigate the effects of ACR and SN on the levels of Hsp27, Hsp70, and Hsp90, western blot analysis was performed to detect the levels of these proteins in heart of mice. As shown in Figures 12(a), 12(b), 13(a), 13(b), 14(a), and 14(b), no significant changes in the levels of Hsp27, Hsp70, and Hsp90 were observed in ACR-treated mice compared to the vehicle-control, and the levels of these proteins were not different significantly in all groups $(P>$ $0.05)$.

\section{Discussion}

Silymarin, a polyphenolic flavonoid, is isolated from the seeds and fruits of milk thistle. Antioxidant and antiapoptotic effects of SN have been reported in many studies [17, 21, $23,24]$. ACR is a ubiquitous environmental pollutant and has important relevance to public health. It is reported that large amounts of ACR are present in foods, cigarette smoke, water, 


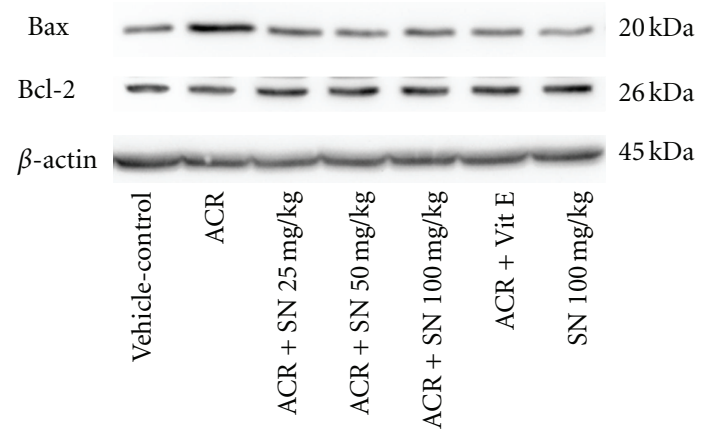

(a)

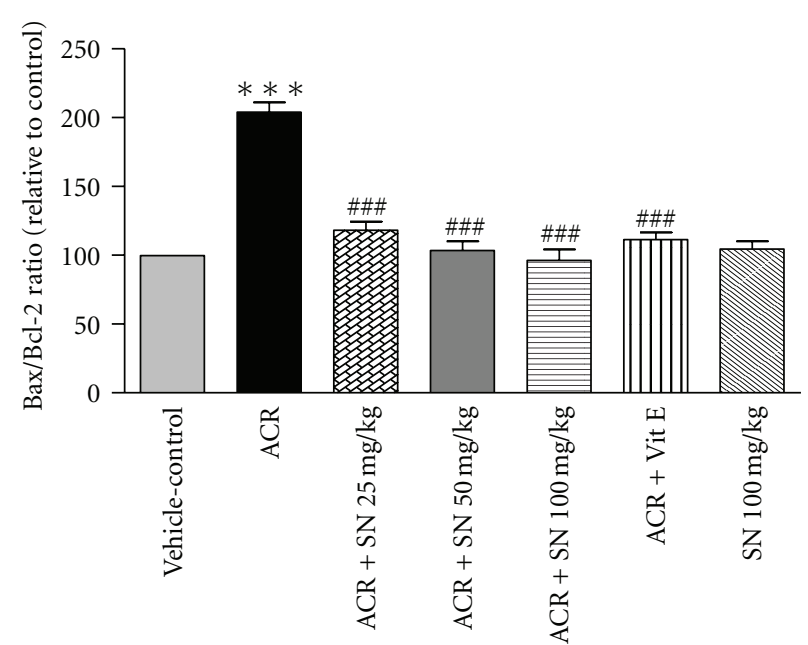

(b)

FIGURE 8: The effect of ACR and SN pretreatment on the protein levels of Bax and Bcl-2 in heart of mice. (a) Representative western blots indicating specific bands for Bax, Bcl-2, and $\beta$-actin as an internal control. Equal amounts of protein sample (50 $\mu \mathrm{g})$ obtained from whole heart homogenate were applied in each lane. These bands are representative of six separate experiments. (b) Densitometric data of protein analysis. Vehicle-control group received normal saline $+0.5 \% \mathrm{w} / \mathrm{v}$ methylcellulose, orally for 3 weeks. ACR was given $(7.5 \mathrm{mg} / \mathrm{kg}$, orally) for 3 weeks. SN was injected 7 days before ACR and daily thereafter throughout the study (3 weeks). Vit E (100 IU/Kg, three times per week) plus ACR were administrated for 3 weeks. SN alone at dose $(100 \mathrm{mg} / \mathrm{kg}$, intraperitoneally) was treated for 4 weeks. Data are expressed as the mean \pm SEM. ${ }^{* * *} P<0.01$ versus vehicle-control group, ${ }^{\# \#} P<0.001$ versus ACR group.

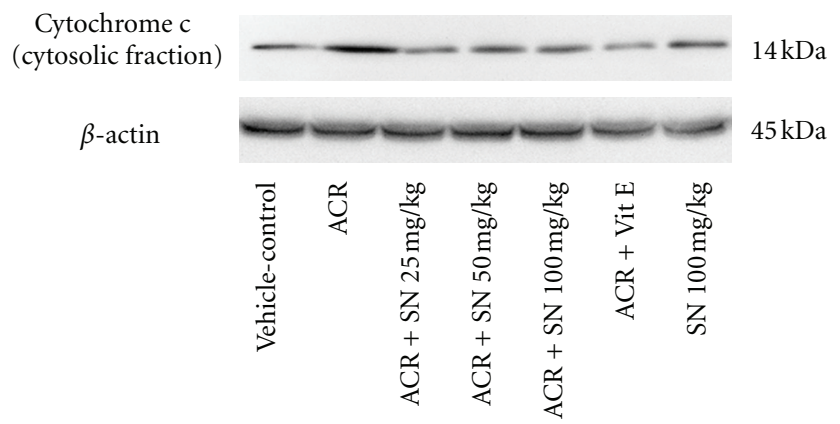

(a)

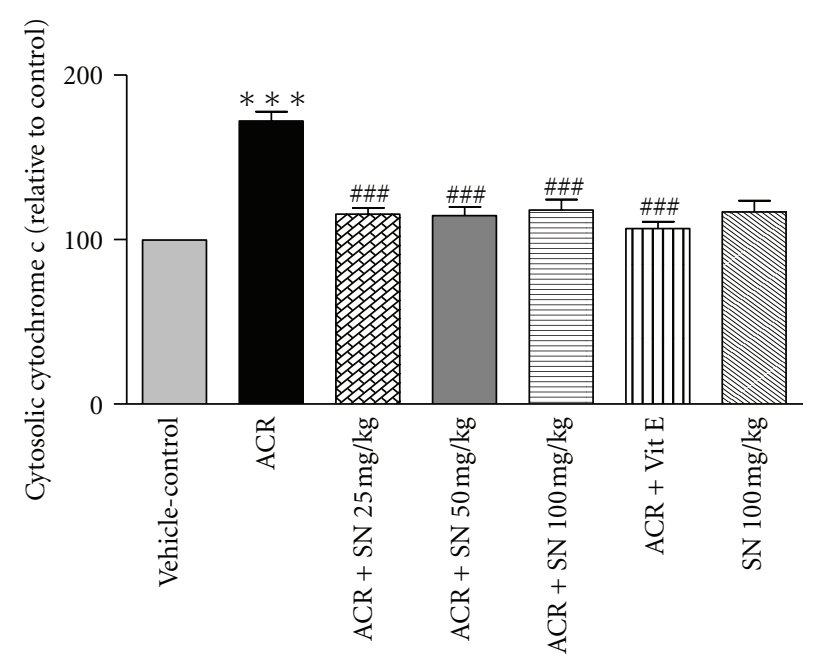

(b)

FIGURE 9: The effect of ACR and SN pretreatment on the protein level of cytochrome $c$ in cytosolic fraction in heart of mice. (a) Representative western blots indicating specific bands for cytochrome $\mathrm{c}$ and $\beta$-actin as an internal control. Equal amounts of protein sample $(50 \mu \mathrm{g})$ obtained from the cytosolic fraction homogenate were applied in each lane. These bands are representative of six separate experiments. (b) Densitometric data of protein analysis. Vehicle-control group received normal saline $+0.5 \%$ w/v methylcellulose, orally for 3 weeks. ACR was given $(7.5 \mathrm{mg} / \mathrm{kg}$, orally) for 3 weeks. SN was injected 7 days before ACR and daily thereafter throughout the study ( 3 weeks). Vit E (100 IU/Kg, three times per week) plus ACR were administrated for 3 weeks. SN alone at dose (100 mg/kg, intraperitoneally) was treated for 4 weeks. Data are expressed as the mean \pm SEM. ${ }^{* * *} P<0.01$ versus vehicle-control group, ${ }^{\# \#} P<0.001$ versus ACR group. 


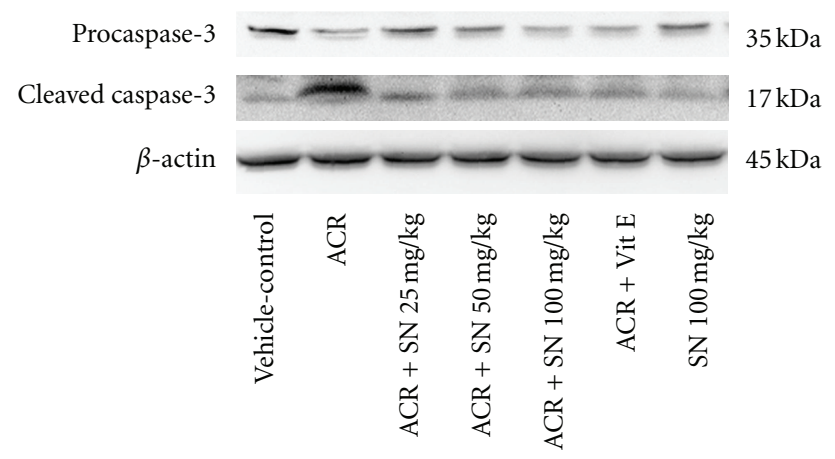

(a)

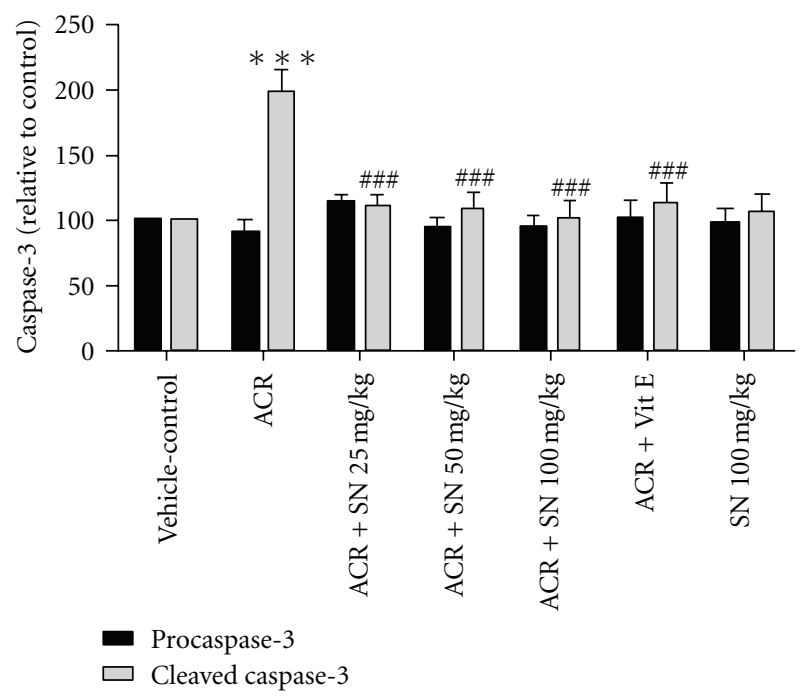

(b)

FIgure 10: The effect of ACR and SN pretreatment on the protein level of caspase-3 (pro- and cleaved caspase-3) in heart of mice. (a) Representative western blots indicating specific bands for procaspase-3, cleaved caspase-3, and $\beta$-actin as an internal control. Equal amounts of protein sample $(50 \mu \mathrm{g})$ obtained from whole heart homogenate were applied in each lane. These bands are representative of six separate experiments. (b) Densitometric data of protein analysis. Vehicle-control group received normal saline $+0.5 \% \mathrm{w} / \mathrm{v}$ methylcellulose, orally for 3 weeks. ACR was given $(7.5 \mathrm{mg} / \mathrm{kg}$, orally) for 3 weeks. SN was injected 7 days before ACR and daily thereafter throughout the study (3 weeks). Vit E (100 IU/Kg, three times per week) plus ACR were administrated for 3 weeks. SN alone at dose $(100 \mathrm{mg} / \mathrm{kg}$, intraperitoneally) was treated for 4 weeks. Data are expressed as the mean \pm SEM. ${ }^{* * *} P<0.01$ versus vehicle-control group, ${ }^{\# \# \# ~} P<0.001$ versus ACR group.

heated oils, automobile exhaust, and coal [2]. Some studies reported that the detrimental and cardiotoxic effect of ACR is related to the generation of ROS and lipid peroxidation $[8,9]$. Oxidative stress and peroxidation of lipid have an important role in many disorders like heart diseases [12]. The main objective of this study was to investigate the protective effects of SN against ACR-induced cardiotoxicity in mice.

The results showed that cardiac level of MDA was significantly increased, while content of GSH was significantly decreased following ACR administration as compared to

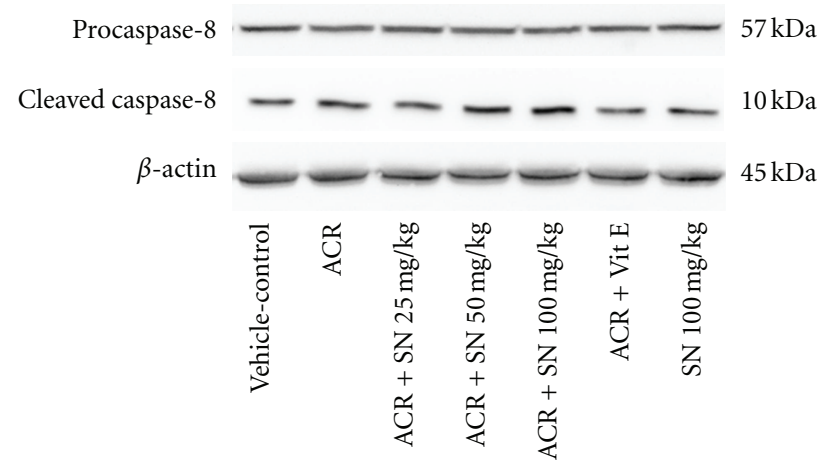

(a)

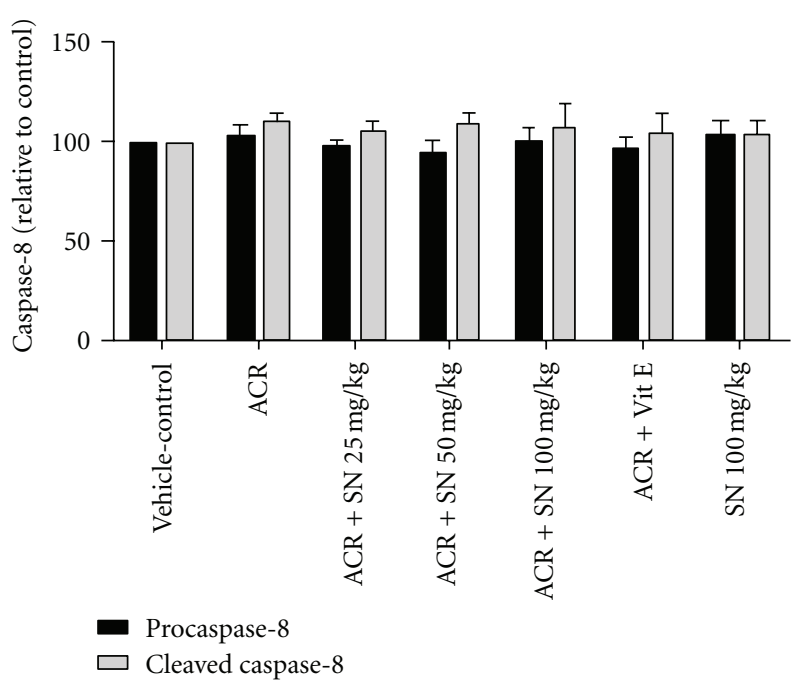

(b)

FIgURE 11: The effect of ACR and SN pretreatment on the protein level of caspase- 8 (pro- and cleaved caspase-8) in heart of mice. (a) Representative western blots indicating specific bands for procaspase-8, cleaved caspase- 8 , and $\beta$-actin as an internal control. Equal amounts of protein sample $(50 \mu \mathrm{g})$ obtained from whole heart homogenate were applied in each lane. These bands are representative of six separate experiments. (b) Densitometric data of protein analysis. Vehicle-control group received normal saline $+0.5 \% \mathrm{w} / \mathrm{v}$ methylcellulose, orally for 3 weeks. ACR was given $(7.5 \mathrm{mg} / \mathrm{kg}$, orally) for 3 weeks. SN was injected 7 days before ACR and daily thereafter throughout the study (3 weeks). Vit E (100 IU/Kg, three times per week) plus ACR were administrated for 3 weeks. SN alone at dose ( $100 \mathrm{mg} / \mathrm{kg}$, intraperitoneally) was treated for 4 weeks. Data are expressed as the mean \pm SEM. $P>0.05$.

vehicle-control group. Oxidative stress induces the lipid peroxidation, and that is due to the interaction between free radicals of diverse origin and cell membrane unsaturated fatty acids. This condition leads to accumulation of several toxic products and MDA. The level of MDA is considered to be an appropriate indicator of lipid peroxidation [26]. These data demonstrated that ACR induced oxidative stress and lipid proxidation of membrane unsaturated fatty acids. Our results are in agreement with other studies which reported that ACR can induce cardiotoxicity due to oxidative stress and rapid depletion of GSH $[6,9]$. The lipid peroxidation 


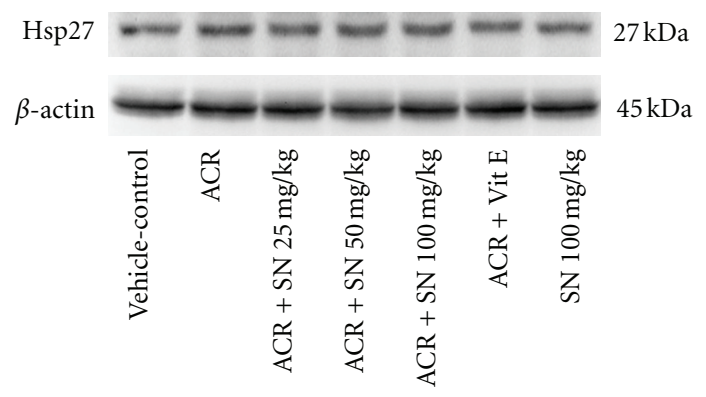

(a)

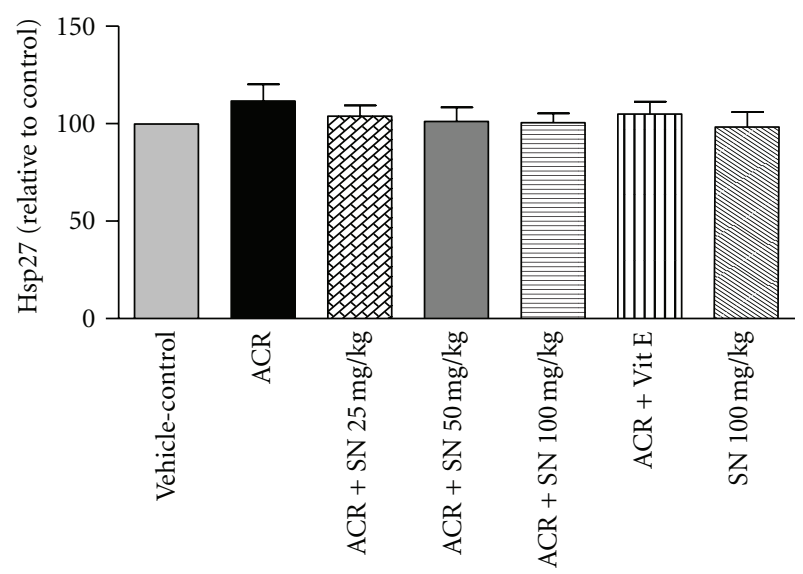

(b)

FIGURE 12: The effect of ACR and SN pretreatment on the protein level of Hsp27 in heart of mice. (a) Representative western blots indicating specific bands Hsp27 and $\beta$-actin as an internal control. Equal amounts of protein sample $(50 \mu \mathrm{g})$ obtained from whole heart homogenate were applied in each lane. These bands are representative of six separate experiments. (b) Densitometric data of protein analysis vehicle-control group received normal saline $+0.5 \% \mathrm{w} / \mathrm{v}$ methylcellulose, orally for 3 weeks. ACR was given $(7.5 \mathrm{mg} / \mathrm{kg}$, orally) for 3 weeks. SN was injected 7 days before ACR and daily thereafter throughout the study (3 weeks). Vit E (100 IU/Kg, three times per week) plus ACR were administrated for 3 weeks. SN alone at dose $(100 \mathrm{mg} / \mathrm{kg}$, intraperitoneally) was treated for 4 weeks. Data are expressed as the mean \pm SEM. $P>0.05$.

induced by ACR may be attributed to the generation of oxygen free radicals. It is possible that some mechanisms are involved. First, ACR can be metabolized to superoxide by xanthine oxidase or aldehyde dehydrogenase. Second, ACR increased ROS production by rapid depletion of endogenous antioxidants, like GSH $[38,39]$. Also, cardiac tissue is very sensitive to oxidative damages due to its highly oxidative metabolism and lower antioxidant systems [24]. Data indicated that administration of SN significantly protected against ACR-induced cardiotoxicity through the inhibition of lipid peroxidation and the increase in GSH content. Several investigations have demonstrated the antioxidant properties of SN in different models. In some studies, it was shown that SN could attenuate lipid peroxidation induced by doxorubicin in heart, liver, and kidney $[24,26]$. Also, SN can improve the cisplatin-induced cardiotoxicity including the oxidative stress and decrease in GSH content [27]. The protective effect of SN may be related to antioxidant activities because of its effects as lipid peroxidation inhibitor and plasma membrane stabilizer and its stimulation for antioxidants $[24,27]$. In addition, antioxidants containing thiol groups like reduced GSH are one of the important cellular defenses against free radicals and oxidative stress. The content of reduced GSH and total thiols are a marker of oxidative damage in heart tissue. GSH acts as scavenger of free radicals and eliminates several xenobiotics [31].

According to data, SN pretreatment ameliorated ACR toxicity by increasing of GSH content in cardiac tissues. However, the content of GSH in the heart was not changed after treatment of mice with $\mathrm{SN}$ alone at dose $100 \mathrm{mg} / \mathrm{Kg}$ compared to vehicle-control, and our results are in agreement with other reports which indicate that treatment with $\mathrm{SN}$ alone has not changed the level of GSH in liver, heart, and kidney $[23,24,40]$.

Current data showed that the activities of the cardiac antioxidant enzymes CAT and SOD were significantly decreased in response to ACR administration compared to vehicle-control group. These findings supported the previously observed GSH depletion and MDA accumulation in heart tissues. The deleterious effect of ACR on the activities of CAT and SOD has been reported in some tissues and cell types $[41,42]$. The decrease in SOD and CAT activities may be related to the elevation of superoxide radical generation during ACR metabolism. Antioxidant enzymes such as SOD and CAT are implicated to be the first line of biological defense against oxidative stress [31]. The SOD transforms superoxide radicals into hydrogen peroxide and $\mathrm{O}_{2}$, and CAT converts hydrogen peroxide into $\mathrm{H}_{2} \mathrm{O}$ and $\mathrm{O}_{2}$. Therefore, SOD and CAT play an important role in the elimination of ROS [43]. The reduction in the activities of antioxidant enzymes can be elucidated on the basis of their exhaustion against oxidative damages [44].

It is reported that neuroprotective effect of $\mathrm{SN}$ may be due to improvement in antioxidant defense system in focal ischemic rats [45]. In addition, SN can increase antioxidant enzyme activity in liver fibrosis induced by thioacetamide in rats [46]. Our results showed that SN pretreatment can improve the antioxidant enzymes activities in heart tissues.

ACR administration to mice significantly increased serum cTnI and CK-MB levels compared to the vehiclecontrol. The increased level of cTnI and CK-MB in ACRtreated group can be attributed to cardiac damage, and this is confirmed by the pathologic findings of this organ. In contrast, SN pretreatment significantly inhibited ACRinduced elevation in serum levels of cTnI and CK-MB. In fact, cTnI is considered to be a very sensitive, specific, and persistent marker of myocardial injury, and CK-MB is one of the available indicators for the diagnosis of heart damage [47]. Our results are in consonance with previous study which reported that SN improved cisplatininduced cardiotoxicity by decreasing the levels of serum CK$\mathrm{MB}$ and plasma cTnI [27]. The protective effect of SN is associated with inhibition of lipid peroxidation activity that leads to stabilizing of plasma membranes and prevents the release of cardiac enzymes. Also, histopathological findings 


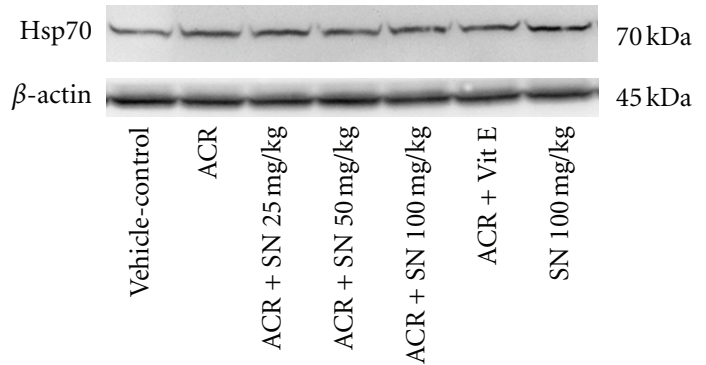

(a)

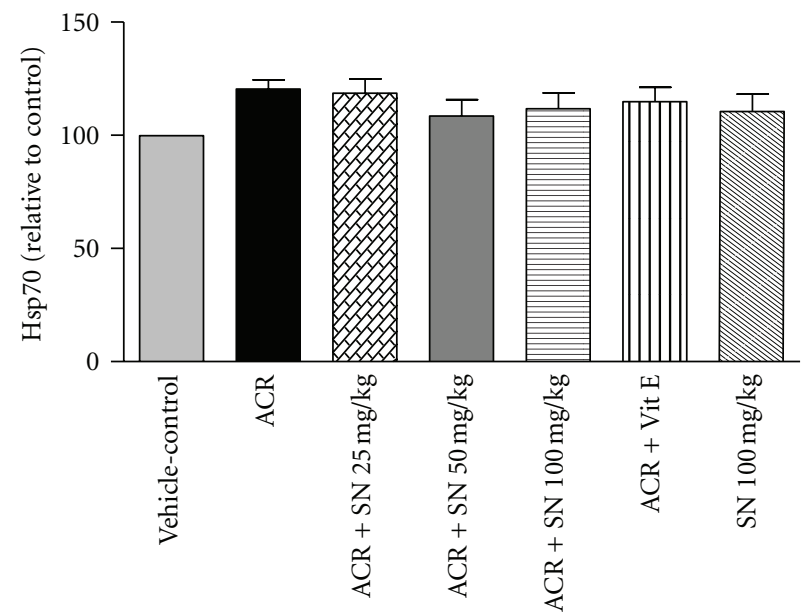

(b)

FIGURE 13: The effect of ACR and SN pretreatment on the protein level of Hsp70 in heart of mice. (a) Representative western blots indicating specific bands for Hsp70 and $\beta$-actin as an internal control. Equal amounts of protein sample ( $50 \mu \mathrm{g})$ obtained from whole heart homogenate were applied in each lane. These bands are representative of six separate experiments. (b) Densitometric data of protein analysis. Vehiclecontrol group received normal saline $+0.5 \% \mathrm{w} / \mathrm{v}$ methylcellulose, orally for 3 weeks. ACR was given $(7.5 \mathrm{mg} / \mathrm{kg}$, orally) for 3 weeks. SN was injected 7 days before ACR and daily thereafter throughout the study ( 3 weeks). Vit E (100 IU/Kg, three times per week) plus ACR were administrated for 3 weeks. SN alone at dose $(100 \mathrm{mg} / \mathrm{kg}$, intraperitoneally) was treated for 4 weeks. Data are expressed as the mean \pm SEM. $P>0.05$.

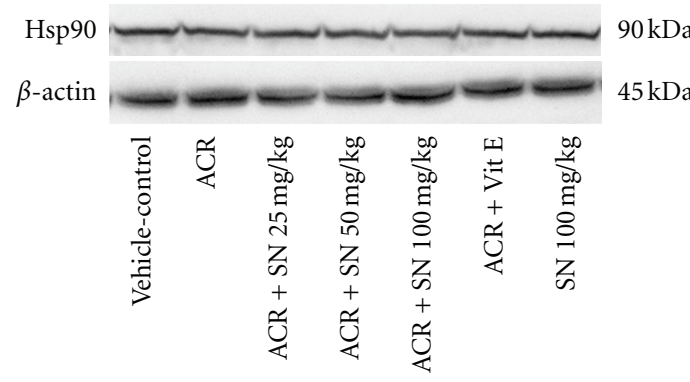

(a)

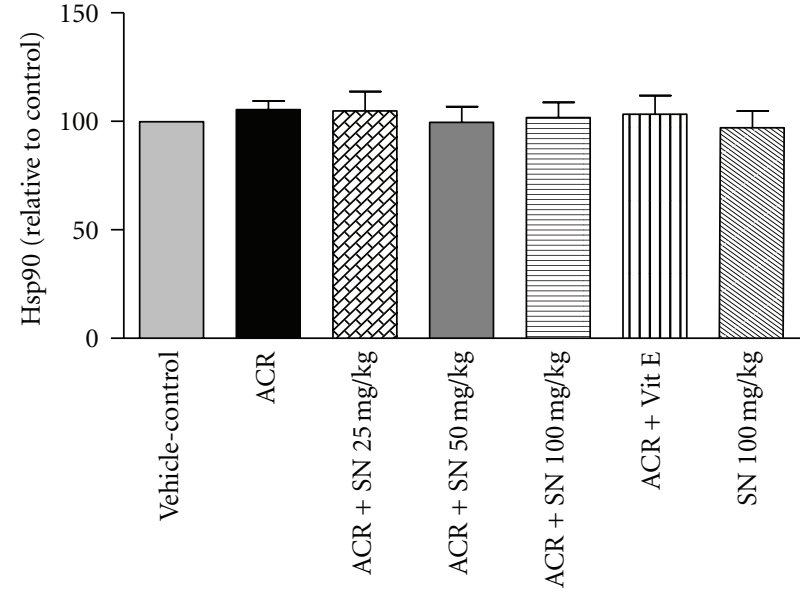

(b)

FIGURE 14: The effect of ACR and SN pretreatment on the protein level of Hsp90 in heart of mice. (a) Representative western blots indicating specific bands for Hsp90 and $\beta$-actin as an internal control. Equal amounts of protein sample ( $50 \mu \mathrm{g})$ obtained from whole heart homogenate were applied in each lane. These bands are representative of six separate experiments. (b) Densitometric data of protein analysis vehiclecontrol group received normal saline $+0.5 \% \mathrm{w} / \mathrm{v}$ methylcellulose, orally for 3 weeks. ACR was given $(7.5 \mathrm{mg} / \mathrm{kg}$, orally) for 3 weeks. SN was injected 7 days before ACR and daily thereafter throughout the study ( 3 weeks). Vit E (100 IU/Kg, three times per week) plus ACR were administrated for 3 weeks. SN alone at dose $(100 \mathrm{mg} / \mathrm{kg}$, intraperitoneally) was treated for 4 weeks. Data are expressed as the mean \pm SEM. $P>0.05$.

indicated that $\mathrm{SN}$ pretreatment protected against ACRinduced toxicity due to the decrease of cardiac damages in these animals. Therefore, the reduction in leakage of these indicators may be related to stability of the cardiomyocyte integrity.

ACR-induced apoptosis in cardiac tissue was assessed by western blot analysis of proteins involved in apoptotic pathway. The results showed that ACR induced apoptosis through the increase in the $\mathrm{Bax} / \mathrm{Bcl}-2$ ratio which caused the elevation of cytochrome $\mathrm{c}$ in the cytoplasm. The increase in the cytosolic fraction of cytochrome $c$ activated caspase3 and raised the level of cleaved caspase- 3 which led to apoptosis induction in cardiac tissues. However, the results exerted no significant change in the level of cleaved caspase8 in ACR-treated group compared to the vehicle-control. Other study indicated that ACR toxicity may be partly due 
to the induction of apoptosis. It has been reported that ACR causes apoptosis in A549 human lung cells through the mitochondrial pathway which may be mediated by the reactive oxygen species [35]. ACR can provoke apoptosis in the adult mice cardiomyocytes by increasing intracellular oxygen free radicals and calcium concentration [9]. Also, it has been demonstrated that long-term oral treatment of ACR induces oxidative stress and apoptosis in the heart of mice [6].

It is known that oxidative stress and the decrease in antioxidant capacity of cells may be an important mediator of apoptotic cell death $[48,49]$. Also, cardiac muscle cells after differentiation have lost their proliferative activity, and apoptotic inducer can considerably damage this organ [27]. The mitochondrial and death receptor pathways are two main apoptotic processes in biological systems [16]. The balance between pro- and antiapoptotic proteins of the Bcl2 family plays a crucial role in progression of apoptosis, so the ratio of $\mathrm{Bax} / \mathrm{Bcl}-2$ and libration of cytochrome $\mathrm{c}$ from mitochondria to the cytoplasm are considered in assessment of apoptosis [33, 50]. Indeed, the release of cytochrome $\mathrm{c}$ from the mitochondria to the cytosol induces the activation of caspase- 3 in cells [16]. Caspase- 8 , the initiator caspase, may be induced by cell surface death receptors. Administration of ACR to mice indicated no significant alteration in caspase- 8 activity, so the extrinsic pathway of apoptosis might have a minor effect in the toxicity of ACR in cardiac tissues of mice. While ACR can activate the mitochondrial pathway of apoptosis through the increase in $\mathrm{Bax} / \mathrm{Bcl}-2$ ratio and the elevation of cytochrome $\mathrm{c}$ in cytoplasm followed by an increase in the level of cleaved caspase- 3 in heart of ACR-treated group, it is reported that the mitochondrial pathway of apoptosis is induced by several factors such as oxidative stress and exposure to toxic substances. Therefore, ACR-induced mitochondrial pathway of apoptosis may be mediated by generation of oxidants and reactive oxygen species, decrease in antioxidant capacity, and finally induction of oxidative stress [35].

According to data, SN can attenuate apoptosis induced by ACR in heart of mice. Administration of $\mathrm{SN}$ reduced the ratio of Bax/Bcl-2 and cytochrome c level in cytosolic fraction. The reduction of the cytosolic cytochrome $\mathrm{c}$ decreased the activation of caspase-3 which led to antiapoptotic effect of $\mathrm{SN}$ in cardiac tissue. These results suggested that $\mathrm{SN}$ could alleviate cardiac injury caused by ACR through suppressing mitochondrial pathway of apoptosis. Our results are in agreement to other studies that reported antiapoptotic properties of SN against toxicity and detrimental effects of cisplatin, doxorubicin, and lead on heart and liver tissues $[26,27,51]$.

The results showed that the levels of Hsp27, Hsp70, and Hsp90 did not reveal significant changes in ACR-treated mice compared to the vehicle-control. The cytoprotective activities of Hsps have been indicated in some pieces of research especially in vitro; however, these effects have not always been observed in vivo studies [52]. In the condition that cell death occurs within a short period, this may not allow time for the effective delivery of Hsps induces to damage sites or fast rearrangement of Hsps to exert their protective roles in a timely manner $[37,52]$. It is possible that the level of Hsps has changed during the treatment protocol, but at the time of sampling, we could not observe the increased level of them. It seems that expression of Hsps depends on many factors such as time of sampling, tissue types, severity of cell injury, stress inducer, and protective mediator [53].

\section{Conclusion}

Our data indicate that SN has protective effects against ACR-induced cardiotoxicity in mice through attenuating lipid peroxidation, increasing GSH content, renewing the activities of antioxidant enzymes, and alleviating apoptosis by modulating $\mathrm{Bax} / \mathrm{Bcl}-2$ ratio, the cytosolic cytochrome $\mathrm{c}$ content, and the level of cleaved caspase- 3 .

\section{Abbreviations}

ACR: Acrolein

SN: Silymarin

Vit E: Vitamin E

MDA: Malondialdehyde

cTnI: Cardiac troponin I

CK-MB: Creatine kinase-MB

GSH: Glutathione

SOD: Superoxide dismutase

CAT: Catalase

ROS: $\quad$ Reactive oxygen species

BUN: Blood urea nitrogen

ALT: $\quad$ Alanine aminotransferase

AST: $\quad$ Aspartate aminotransferase

NO: $\quad$ Nitric oxide

GSHPx: Glutathione peroxidase

iNOS: Inducible nitric oxide synthase

MT: $\quad$ Metallothionein I-II

PMSF: Phenylmethanesulfonyl fluoride

SDS: $\quad$ Sodium dodecyl sulphate

TEMED: $\mathrm{N}, \mathrm{N}, \mathrm{N}^{\prime}, \mathrm{N}^{\prime}$-Tetramethylethylenediamine

$\beta$-ME: $\quad \beta$-Mercaptoethanol

TBA: Thiobarbituric acid

PVDF: Polyvinylidene fluoride

BSA: Bovine serum albumin

PBS: $\quad$ Phosphate buffered saline

DTNB: 5,5'-dithiobis(2-nitrobenzoic acid)

TNB: 5-thio-2-nitrobenzoic acid

TCA: Trichloroacetic acid

EDTA: Ethylenediaminetetraacetic acid

EGTA: Ethylene glycol-bis(2-aminoethylether)$\mathrm{N}, \mathrm{N}, \mathrm{N}^{\prime}, \mathrm{N}^{\prime}$-tetraacetic

acid

Hsps: Heat shock proteins.

\section{Conflict of Interests}

The authors declare that there is no conflict of interests. 


\section{Acknowledgment}

The authors are thankful to the Vice Chancellor of Research, Mashhad University of Medical Sciences for financial support. The results described in this paper are part of a Ph.D. degree thesis.

\section{References}

[1] J. F. Stevens and C. S. Maier, "Acrolein: sources, metabolism, and biomolecular interactions relevant to human health and disease," Molecular Nutrition and Food Research, vol. 52, no. 1, pp. 7-25, 2008.

[2] O. Faroon, N. Roney, J. Taylor, A. Ashizawa, M. H. Lumpkin, and D. J. Plewak, "Acrolein health effects," Toxicology and Industrial Health, vol. 24, no. 7, pp. 447-490, 2008.

[3] J. Luo, B. G. Hill, Y. Gu et al., "Mechanisms of acroleininduced myocardial dysfunction: implications for environmental and endogenous aldehyde exposure," American Journal of Physiology, vol. 293, no. 6, pp. H3673-H3684, 2007.

[4] V. J. Feron, H. P. Til, F. De Vrijer, R. A. Woutersen, F. R. Cassee, and P. J. Van Bladeren, "Aldehydes: occurrence, carcinogenic potential, mechanism of action and risk assessment," Mutation Research, vol. 259, no. 3-4, pp. 363-385, 1991.

[5] D. P. Ghilarducci and R. S. Tjeerdema, "Fate and effects of acrolein," Reviews of Environmental Contamination and Toxicology, vol. 144, pp. 95-146, 1995.

[6] M. A. Ismahil, T. Hamid, and P. Haberzettl, "Chronic oral exposure to the aldehyde pollutant acrolein induces dilated cardiomyopathy," American Journal of Physiology, vol. 301, no. 5, pp. H2050-H2060, 2011.

[7] K. Uchida, M. Shiraishi, Y. Naito, Y. Torii, Y. Nakamura, and T. Osawa, "Activation of stress signaling pathways by the end product of lipid peroxidation: 4-hydroxy-2-nonenal is a potential inducer of intracellular peroxide production," Journal of Biological Chemistry, vol. 274, no. 4, pp. 2234-2242, 1999.

[8] J. Luo and R. Shi, "Acrolein induces oxidative stress in brain mitochondria," Neurochemistry International, vol. 46, no. 3, pp. 243-252, 2005.

[9] L. Wang, Y. Sun, M. Asahi, and K. Otsu, "Acrolein, an environmental toxin, induces cardiomyocyte apoptosis via elevated intracellular calcium and free radicals," Cell Biochemistry and Biophysics, vol. 61, no. 1, pp. 131-136, 2011.

[10] S. Srivastava, B. Chandrasekar, A. Bhatnagar, and S. D. Prabhu, "Lipid peroxidation-derived aldehydes and oxidative stress in the failing heart: role of aldose reductase," American Journal of Physiology, vol. 283, no. 6, pp. H2612-H2619, 2002.

[11] K. K. Griendling and G. A. FitzGerald, "Oxidative stress and cardiovascular injury-part II: animal and human studies," Circulation, vol. 108, no. 17, pp. 2034-2040, 2003.

[12] V. P. M. van Empel, A. T. Bertrand, R. J. van Oort et al., "EUK8 , a superoxide dismutase and catalase mimetic, reduces cardiac oxidative stress and ameliorates pressure overloadinduced heart failure in the harlequin mouse mutant," Journal of the American College of Cardiology, vol. 48, no. 4, pp. 824832, 2006.

[13] S. Pugazhenthi, K. Phansalkar, G. Audesirk, A. West, and L. Cabell, "Differential regulation of c-jun and CREB by acrolein and 4-hydroxynonenal," Free Radical Biology and Medicine, vol. 40, no. 1, pp. 21-34, 2006.
[14] A. Tanel and D. A. Averill-Bates, "Activation of the death receptor pathway of apoptosis by the aldehyde acrolein," Free Radical Biology and Medicine, vol. 42, no. 6, pp. 798-810, 2007.

[15] S. Orrenius and B. Zhivotovsky, "The future of toxicologydoes it matter how cells die?" Chemical Research in Toxicology, vol. 19, no. 6, pp. 729-733, 2006.

[16] S. Elmore, "Apoptosis: a review of programmed cell death," Toxicologic Pathology, vol. 35, no. 4, pp. 495-516, 2007.

[17] G. Karimi, M. Vahabzadeh, P. Lari, M. Rashedinia, and M. Moshiri, "Silymarin, a promising pharmacological agent for treatment of diseases," Iranian Journal of Basic Medical Sciences, vol. 14, no. 4, pp. 308-317, 2011.

[18] H. Malekinejada, A. Rezabakhsha, F. Rahmanib, and R. Hobbenaghic, "Silymarin regulates the cytochrome P450 3A2 and glutathione peroxides in the liver of streptozotocininduced diabetic rats," Phytomedicine, vol. 19, no. 7, pp. 583$590,2012$.

[19] F. Nazemian, G. Karimi, M. Moatamedi, S. Charkazi, J. Shamsara, and A. H. Mohammadpour, "Effect of silymarin administration on TNF- $\alpha$ serum concentration in peritoneal dialysis patients," Phytotherapy Research, vol. 24, no. 11, pp. 1654-1657, 2010.

[20] C. H. Chen, T. S. Huang, C. H. Wong et al., "Synergistic anticancer effect of baicalein and silymarin on human hepatoma HepG2 Cells," Food and Chemical Toxicology, vol. 47, no. 3, pp. 638-644, 2009.

[21] T. Fleming, PDR for Herbal Medicines, New Jersy Medical Economics Company, 2000.

[22] G. Karimi, M. Ramezani, and Z. Tahoonian, "Cisplatin nephrotoxicity and protection by milk thistle extract in rats," Evidence-Based Complementary and Alternative Medicine, vol. 2, no. 3, pp. 383-386, 2005.

[23] H. H. Mansour, F. Hafez, and N. M. Fahmy, "Silymarin modulates cisplatin-induced oxidative stress and hepatotoxicity in rats," Journal of Biochemistry and Molecular Biology, vol. 39, no. 6, pp. 656-661, 2006.

[24] N. A. El-Shitany, S. El-Haggar, and K. El-desoky, "Silymarin prevents adriamycin-induced cardiotoxicity and nephrotoxicity in rats," Food and Chemical Toxicology, vol. 46, no. 7, pp. 2422-2428, 2008.

[25] R. Tunca, M. Sozmen, M. Citil, M. Karapehlivan, S. Erginsoy, and K. Yapar, "Pyridine induction of cytochrome P450 1A1, iNOS and metallothionein in Syrian hamsters and protective effects of silymarin," Experimental and Toxicologic Pathology, vol. 61, no. 3, pp. 243-255, 2009.

[26] N. Patel, C. Joseph, G. B. Corcoran, and S. D. Ray, "Silymarin modulates doxorubicin-induced oxidative stress, Bcl-xL and p53 expression while preventing apoptotic and necrotic cell death in the liver," Toxicology and Applied Pharmacology, vol. 245, no. 2, pp. 143-152, 2010.

[27] E. S. E. El-Awady, Y. M. Moustafa, D. M. Abo-Elmatty, and A. Radwan, "Cisplatin-induced cardiotoxicity: mechanisms and cardioprotective strategies," European Journal of Pharmacology, vol. 650, no. 1, pp. 335-341, 2011.

[28] A. T. Hariri, S. A. Moallem, M. Mahmoudi, B. Memar, and H. Hosseinzadeh, "Sub-acute effects of diazinon on biochemical indices and specific biomarkers in rats: protective effects of crocin and safranal," Food and Chemical Toxicology, vol. 48, no. 10 , pp. 2803-2808, 2010.

[29] W. G. Niehaus and J. R. B. Samuelsson, "Formation of malonaldehyde from phospholipid arachidonate during microsomal lipid peroxidation," European Journal of Biochemistry, vol. 6, no. 1, pp. 126-130, 1968. 
[30] M. S. Moron, J. W. Depierre, and B. Mannervik, "Levels of glutathione, glutathione reductase and glutathione Stransferase activities in rat lung and liver," Biochimica et Biophysica Acta, vol. 582, no. 1, pp. 67-78, 1979.

[31] P. Manna, M. Sinha, and P. C. Sil, "Amelioration of cadmiuminduced cardiac impairment by taurine," Chemico-Biological Interactions, vol. 174, no. 2, pp. 88-97, 2008.

[32] E. Herman, R. Mhatre, I. P. Lee, J. Vick, and V. S. Waravdekar, "A comparison of the cardiovascular actions of daunomycin, adriamycin and $\mathrm{N}$-acetyldaunomycin in hamsters and monkeys," Pharmacology, vol. 6, no. 4, pp. 230-241, 1971.

[33] S. J. Korsmeyer, "BCL-2 gene family and the regulation of programmed cell death," Cancer Research, vol. 59, no. 7, pp. 1693s-1700s, 1999.

[34] B. Liu, Z. Jian, Q. Li et al., "Baicalein protects human melanocytes from $\mathrm{H}_{2} \mathrm{O}_{2}$-induced apoptosis via inhibiting mitochondria-dependent caspase activation and the p38 MAPK pathway," Free Radical Biology and Medicine, vol. 53, no. 2, pp. 183-193, 2012.

[35] J. Roy, P. Pallepati, A. Bettaieb, A. Tanel, and D. A. AverillBates, "Acrolein induces a cellular stress response and triggers mitochondrial apoptosis in A549 cells," Chemico-Biological Interactions, vol. 181, no. 2, pp. 154-167, 2009.

[36] H. D. Yuan, G. Z. Jin, and G. C. Piao, "Hepatoprotective effects of an active part from Artemisia sacrorum Ledeb. against acetaminophen-induced toxicity in mice," Journal of Ethnopharmacology, vol. 127, no. 2, pp. 528-533, 2010.

[37] A. S. Sreedhar and P. Csermely, "Heat shock proteins in the regulation of apoptosis: new strategies in tumor therapy-a comprehensive review," Pharmacology and Therapeutics, vol. 101, no. 3, pp. 227-257, 2004.

[38] J. D. Adams Jr. and L. K. Klaidman, "Acrolein-induced oxygen radical formation," Free Radical Biology and Medicine, vol. 15, no. 2, pp. 187-193, 1993.

[39] J. P. Kehrer and S. S. Biswal, "The molecular effects of acrolein,” Toxicological Sciences, vol. 57, no. 1, pp. 6-15, 2000.

[40] G. Ramakrishnan, H. R. B. Raghavendran, R. Vinodhkumar, and T. Devaki, "Suppression of N-nitrosodiethylamine induced hepatocarcinogenesis by silymarin in rats," ChemicoBiological Interactions, vol. 161, no. 2, pp. 104-114, 2006.

[41] N. Arumugam, V. Sivakumar, J. Thanislass, K. Sadasivan Pillai, S. Niranjali Devaraj, and H. Devaraj, "Acute pulmonary toxicity of acrolein in rats-underlying mechanism," Toxicology Letters, vol. 104, no. 3, pp. 189-194, 1999.

[42] Z. Feng, Z. Liu, X. Li et al., " $\alpha$-Tocopherol is an effective Phase II enzyme inducer: protective effects on acroleininduced oxidative stress and mitochondrial dysfunction in human retinal pigment epithelial cells," Journal of Nutritional Biochemistry, vol. 21, no. 12, pp. 1222-1231, 2010.

[43] K. Pradeep, C. V. R. Mohan, K. Gobianand, and S. Karthikeyan, "Silymarin modulates the oxidant-antioxidant imbalance during diethylnitrosamine induced oxidative stress in rats," European Journal of Pharmacology, vol. 560, no. 2-3, pp. 110-116, 2007.

[44] A. A. Elberry, A. B. Abdel-Naim, E. A. Abdel-Sattar et al., "Cranberry (Vaccinium macrocarpon) protects against doxorubicin-induced cardiotoxicity in rats," Food and Chemical Toxicology, vol. 48, no. 5, pp. 1178-1184, 2010.

[45] M. M. Muley, V. N. Thakare, R. R. Patil, A. D. Kshirsagar, and S. R. Naik, "Silymarin improves the behavioural, biochemical and histoarchitecture alterations in focal ischemic rats: a comparative evaluation with piracetam and protocatachuic acid," Pharmacology Biochemistry and Behavior, vol. 102, no. 2, pp. 286-293, 2012.
[46] M. E. Shaker, G. E. Shiha, and T. M. Ibrahim, "Comparison of early treatment with low doses of nilotinib, imatinib and a clinically relevant dose of silymarin in thioacetamide-induced liver fibrosis," European Journal of Pharmacology, vol. 670, no. 2-3, pp. 593-600, 2011.

[47] P. J. O’Brien, D. E. C. Smith, T. J. Knechtel et al., “Cardiac troponin I is a sensitive, specific biomarker of cardiac injury in laboratory animals," Laboratory Animals, vol. 40, no. 2, pp. 153-171, 2006.

[48] B. Fadeel, S. Orrenius, and B. Zhivotovsky, "Apoptosis in human disease: a new skin for the old ceremony?" Biochemical and Biophysical Research Communications, vol. 266, no. 3, pp. 699-717, 1999.

[49] S. Kumar and S. L. Sitasawad, "N-acetylcysteine prevents glucose/glucose oxidase-induced oxidative stress, mitochondrial damage and apoptosis in H9c2 cells," Life Sciences, vol. 84, no. 11-12, pp. 328-336, 2009.

[50] R. Hu, S. Zhou, and X. Li, "Altered Bcl-2 and Bax expression is associated with cultured first trimester human cytotrophoblasts apoptosis induced by hypoxia," Life Sciences, vol. 79, no. 4, pp. 351-355, 2006.

[51] M. G. Shalan, M. S. Mostafa, M. M. Hassouna, S. E. H. ElNabi, and A. El-Refaie, "Amelioration of lead toxicity on rat liver with Vitamin C and silymarin supplements," Toxicology, vol. 206, no. 1, pp. 1-15, 2005.

[52] B. Kalmar and L. Greensmith, "Induction of heat shock proteins for protection against oxidative stress," Advanced Drug Delivery Reviews, vol. 61, no. 4, pp. 310-318, 2009.

[53] T. Ahmed, A. K. Tripathi, S. G. Suke et al., "Role of HSP27 and reduced glutathione in modulating malathioninduced apoptosis of human peripheral blood mononuclear cells: ameliorating effect of N-acetylcysteine and curcumin," Toxicology in Vitro, vol. 23, no. 7, pp. 1319-1325, 2009. 


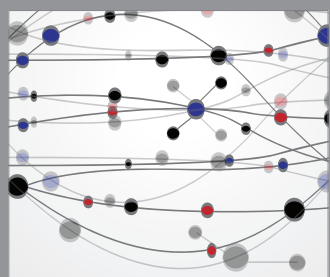

The Scientific World Journal
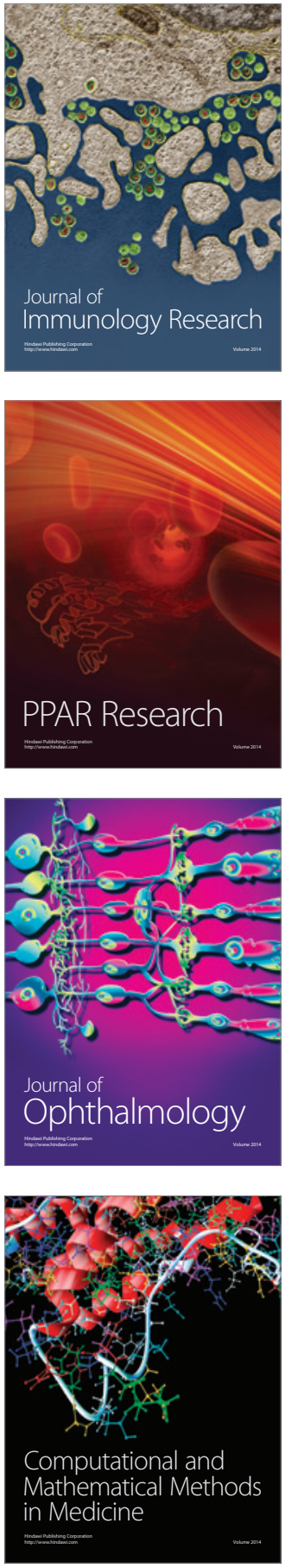

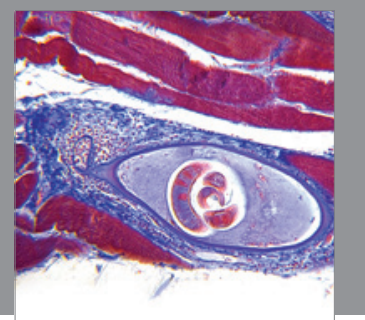

Gastroenterology

Research and Practice
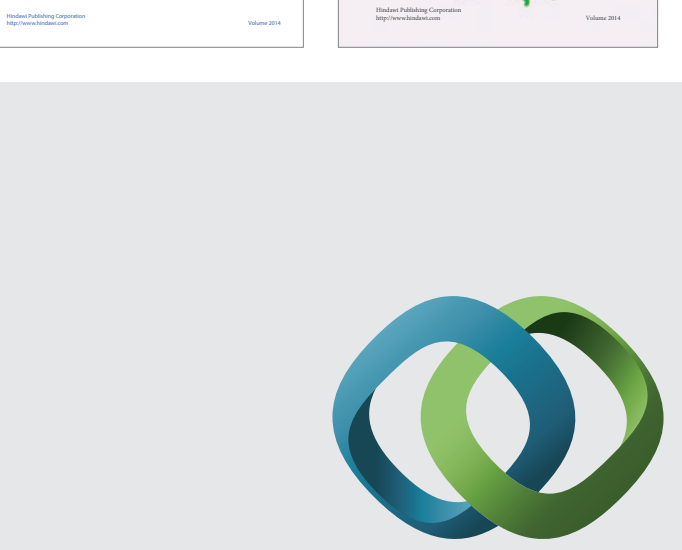

\section{Hindawi}

Submit your manuscripts at

http://www.hindawi.com
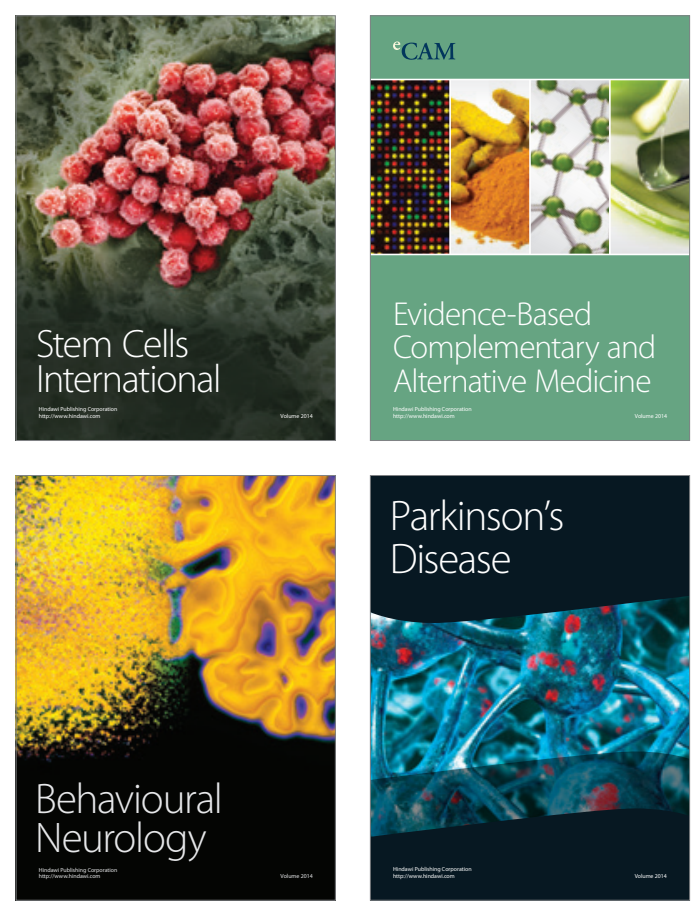

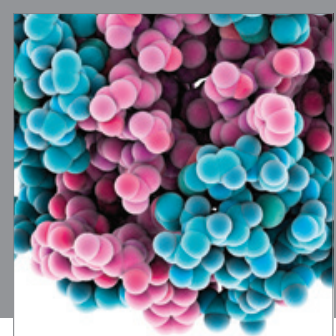

Journal of
Diabetes Research

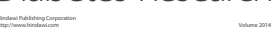

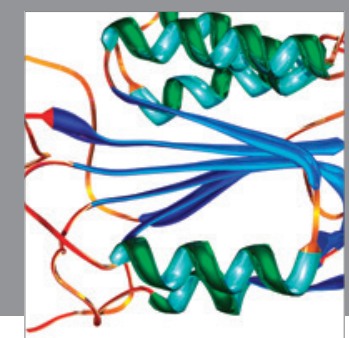

Disease Markers
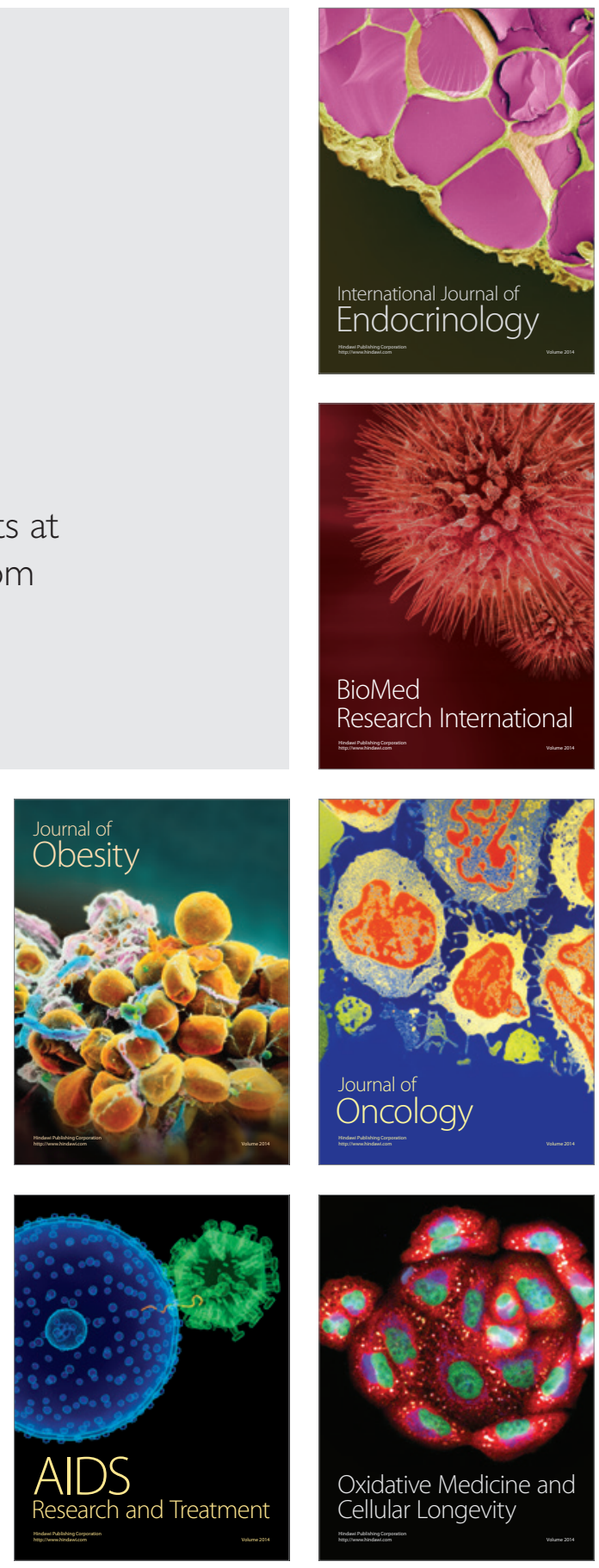